\title{
Impacts of tropical cyclones on the thermodynamic conditions in the tropical tropopause layer observed by A-Train satellites
}

\author{
Jing Feng and Yi Huang \\ Department of Atmospheric and Oceanic Sciences, McGill University, Montréal, Canada
}

Correspondence: Jing Feng (jing.feng3@ mail.mcgill.ca)

Received: 25 February 2021 - Discussion started: 23 April 2021

Revised: 17 September 2021 - Accepted: 17 September 2021 - Published: 18 October 2021

\begin{abstract}
The tropical tropopause layer (TTL) is the transition layer between the troposphere and the stratosphere. Tropical cyclones may impact the TTL by perturbing the vertical distributions of cloud, temperature, and water vapor. This study combines several A-Train instruments, including radar from CloudSat, lidar from the Cloud-Aerosol Lidar and Infrared Pathfinder Satellite Observation (CALIPSO) satellite, and the Atmospheric Infrared Sounder (AIRS) on the Aqua satellite, to detect signatures of cyclone impacts on the distribution patterns of cloud, water vapor, temperature, and radiation by compositing these thermodynamic fields relative to the cyclone center location.

Based on the CloudSat 2B-CLDCLASS-LIDAR product, this study finds that tropical cyclone events considerably increase the occurrence frequencies of TTL clouds, in the form of cirrus clouds above a clear troposphere. The amount of TTL cloud ice, however, is found to be mostly contributed by overshooting deep convection that penetrates the base of the TTL at $16 \mathrm{~km}$.

To overcome the lack of temperature and water vapor products in cloudy conditions, this study implements a synergistic method that retrieves temperature, water vapor, ice water content, and effective radius simultaneously by incorporating observations from AIRS, CloudSat, and CALIPSO. Using the synergistic method, we find a vertically oscillating pattern of temperature anomalies above tropical cyclones, with warming beneath the cloud top (around $16 \mathrm{~km}$ ) and cooling above. Based on water vapor profiles retrieved by the synergistic method, we find that the layer integrated water vapor (LIWV) above $16 \mathrm{~km}$ is higher above tropical cyclones, especially above overshooting deep convective clouds, compared to climatological values.
\end{abstract}

Moreover, we find that the longwave and net radiative cooling effect of clouds prevails within $1000 \mathrm{~km}$ of tropical cyclone centers. The radiative heating effects of clouds from the CloudSat 2B-FLXHR-LIDAR product are well differentiated by the collocated brightness temperature of an infrared window channel from the collocated AIRS L1B product. By performing instantaneous radiative heating rate calculations, we further find that TTL hydration is usually associated with radiative cooling of the TTL, which inhibits the diabatic ascent of moist air across isentropic surfaces to the stratosphere. Therefore, the radiative balance of the TTL under the impact of the cyclone does not favor the maintenance of moist anomalies in the TTL or transporting water vertically to the stratosphere.

\section{Introduction}

The tropical tropopause layer (TTL) is the transition layer between the convective overturning circulation in the troposphere and the Brewer-Dobson circulation in the stratosphere. Once entering the TTL, air tends to rise into the stratosphere, driven by extratropical wave drag and influenced by local radiative heating (Holton et al., 1995; Corti et al., 2006). The clear-sky radiative heating becomes positive above the level of zero radiative heating (LZRH). This level marks the altitude where the ascending motion becomes prevailing.

The TTL plays an important role in stratospheretroposphere exchange (Holton et al., 1995). For example, the low temperature in the TTL acts as a "cold trap" that modulates both the vertical and the isentropic (quasi-horizontal) transport of water vapor to the lower stratosphere (Dessler 
et al., 1995; Brewer, 1949; Holton and Gettelman, 2001; Gettelman et al., 2002), where water vapor, despite its low concentration, may have a large impact on radiation, climate, and atmospheric chemistry (Solomon et al., 2010; Anderson et al., 2012; Dessler et al., 2013; Huang et al., 2016).

Given its vertical extent, deep convection potentially provides an important pathway to transport water vapor and other constituents to the stratosphere via the TTL. Deep convection may affect the TTL in several ways. First, tropical deep convection, especially in tropical cyclones, is associated with strong dynamical cooling around the tropopause level (Holloway and Neelin, 2007). Second, the injected ice and water vapor, together with the temperature anomalies caused by deep convection, can modify the radiative heating in the TTL, which in turn can either speed up or slow down the upwelling motion of air and the transport to the stratosphere. Consequently, air convectively injected into the TTL can be either a source or a sink of water vapor, depending on the pre-existing relative humidity (Ueyama et al., 2018; Schoeberl et al., 2018). Simulations and observations have shown that deep convection may hydrate the upper troposphere and lower stratosphere (UTLS) by directly injecting water vapor and ice above mid-latitudes (Anderson et al., 2012; Sun and Huang, 2015; Qu et al., 2020) and tropical storms (Avery et al., 2017; Schoeberl et al., 2018) or dehydrate it by condensing the pre-existing water vapor into ice particles in supersaturated environments (Ueyama et al., 2018).

On the other hand, climate models and global reanalysis datasets are subject to common problems in representing key processes, such as convective parameterization, (e.g., Takahashi et al., 2016), in the UTLS region. These problems include a persistent wet bias in upper tropospheric humidity (Huang et al., 2007; Jiang et al., 2012, 2015), discrepancies in the transportation speed of water vapor from the upper troposphere to the lower stratosphere (Jiang et al., 2015; Schoeberl et al., 2012), and contradictory assessments of cloud impacts on diabatic heating in the TTL region (Wright and Fueglistaler, 2013; Wright et al., 2020).

Existing satellite datasets (Waters et al., 2006; Bernath et al., 2005; Anthes et al., 2008) and aircraft campaigns (e.g., Jensen et al., 2013; Lee et al., 2019) have advanced understanding of the TTL region, although the study of deep convective impacts on temperature, water vapor, and clouds in the TTL region is still impeded by a lack of collocated measurements of these variables. The A-Train constellation (L'Ecuyer and Jiang, 2011) carries over 20 instruments that monitor clouds and other atmospheric variables. However, the sounding of thermodynamic conditions above deep convection, especially near the convective core, remains a challenge (Livesey et al., 2017; Olsen et al., 2013). Feng and Huang (2018) found that the retrievability of temperature and water vapor is improved by an underlying cloud layer because the cloud layer reduces the degeneracy caused by nonmonotonic vertical temperature variations and the smearing effect of lower-level water vapor, and they proposed a cloud- assisted retrieval algorithm that can be applied to infrared hyperspectral measurements, such as those from the Atmospheric Infrared Sounder (AIRS; Chahine et al., 2006) aboard Aqua (Parkinson, 2003). Feng et al. (2021) further developed a synergistic method that incorporates cloud measurements of collocated active cloud profilers. By conducting a simulation experiment, Feng et al. (2021) demonstrated that this method can capture the variability in temperature and humidity above tropical convective storms and improve the retrievals near the cloud top through the incorporation of information from active sensors.

In this study, we aim to quantify the effect of tropical cyclones on TTL temperature, water vapor, and clouds using A-Train satellite observations, specifically hyperspectral infrared measurements from AIRS and cloud profiles from CloudSat (Stephens et al., 2008) and CALIPSO (CloudAerosol Lidar and the Infrared Pathfinder Satellite Observation; Winker et al., 2010). Tropical cyclones are of particular interest here because they constitute a large fraction of the most energetic (overshooting) convective clouds in the tropics (Romps and Kuang, 2009) and provide vertically extended dense high clouds that enable the above-cloud temperature and humidity retrieval method developed by Feng and Huang (2018) and Feng et al. (2021). By using satellite observational datasets, which are introduced in Sect. 2, we aim to understand the following: (1) how tropical cyclones, especially the overshooting events, impact TTL cloud occurrence and cloud ice (see Sect. 3.1 and 3.2); (2) whether tropical cyclones lead to an overall hydration in the TTL (see Sect. 3.3); and (3) how tropical cyclones affect radiative heating in the TTL (Sect. 4). These questions are further discussed together with key conclusions in Sect. 5.

\section{Data and methodology}

\subsection{Datasets}

Following a sun-synchronized orbit with a repeat cycle of $16 \mathrm{~d}$, the A-Train satellites cross the Equator at around 13:30 local solar time in the ascending nodes and 1:30 local solar time in the descending nodes every day.

CloudSat uses a cloud profiling radar (CPR) that operates at $94 \mathrm{GHz}$ to observe cloud and precipitation. Sampling along the track every $1.1 \mathrm{~km}$, this instrument has a cross-track resolution of $1.4 \mathrm{~km}$ and along-track resolution of $1.8 \mathrm{~km}$. The Cloud-Aerosol Lidar with Orthogonal Polarization (CALIOP) is a polarization lidar carried by CALIPSO that operates at 532 and $1064 \mathrm{~nm}$. The sensitivities of the two instruments in detecting cloud properties differ. The lidar signals are sensitive to cloud particles at all sizes but are quickly attenuated in thick clouds. The radar is not sensitive to clouds with effective particle sizes smaller than $40-50 \mu \mathrm{m}$ but can observe thick clouds and precipitation in storm cores. Hence, it is essential to combine the lidar and radar to obtain the sen- 
sitivity to both optically thin cirrus in the TTL and optically thick deep convective clouds (DCCs).

CloudSat provides several radar-lidar products by merging coincident lidar pulses within the CPR footprints (Mace et al., 2009). In this study, we use the cloud classification (2B-CLDCLASS-LIDAR; Sassen et al., 2009) and radiative heating rate (2B-FLXHR-LIDAR; Henderson et al., 2013) products (version P2_R04). In the 2B-CLDCLASS-LIDAR product, eight cloud types are classified, including cirrus, altostratus, altocumulus, stratus, stratocumulus, cumulus, nimbostratus, and deep convective clouds, depending on the vertical distribution of hydrometeors inferred from radar signal intensity and also their horizontal length scales (Wang et al., 2012). DCCs are classified based on several conditions, including a vast horizontal and vertical extent, dense hydrometers (as inferred from radar reflectivity near the cloud top), and also the presence of precipitation (Wang et al., 2012). The heating rate profiles in 2B-FLXHR-LIDAR are derived from two-stream broadband radiative transfer calculations combining the 2B-CWC-RO cloud water content profile; collocated CALIPSO version-3 products (Trepte et al., 2010); and atmospheric state profiles (temperature, water vapor, and ozone) from ECMWF forecasts, which are included in the ECMWF-AUX product (Partain, 2004).

Operational CloudSat-CALIPSO synergistic algorithms have been developed to retrieve ice cloud properties (Austin et al., 2009; Deng et al., 2010; Okamoto et al., 2010; Delanoë and Hogan, 2010) and are evaluated (Deng et al., 2013; Saito et al., 2017). This study uses a DARDAR-Cloud (raDAR/liDAR; Delanoë and Hogan, 2010) product v2.1.1 which combines coincident lidar attenuated backscatter measurements (from CALIPSO Level $1 \mathrm{v} 3$ ) and radar reflectivity (from 1B-CPR R04). Based on an optimal estimation method (Rodgers, 2000), DARDAR iteratively retrieves the state vector which contains the visible extinction, lidar extinction-tobackscatter ratio, and particle number concentration and converts it to ice water content (IWC) and effective radii profiles at each CPR footprint with a horizontal (cross-track) resolution of $1.4 \mathrm{~km}$ and a vertical resolution of $60 \mathrm{~m}$ following a set of cloud microphysical parameterizations (i.e., particle size distribution and mass-size relation). This study uses IWC profiles from DARDAR but cloud types classified by the CloudSat 2B-CLDCLASS-LIDAR product. Due to differences in retrieval algorithms and cloud microphysical assumptions (Deng et al., 2013), there are discrepancies between the two products in terms of ice cloud occurrence (McErlich et al., 2021). For consistency, we only use footprints where both radar and lidar observations are available and treat a high cloud layer detected by DARDAR but not classified in 2B-CLDCLASS-LIDAR as the same cloud type as its adjacent cloud layer or as cirrus if it is isolated.

The Aura Microwave Limb Sounder (MLS; Waters et al., 2006) retrieves temperature and trace gases for pressure levels less than $316 \mathrm{hPa}$, with a vertical resolution of around $3 \mathrm{~km}$ for water vapor and $4.7 \mathrm{~km}$ for temperature. The doc- umented accuracy of the version-4.2 product at the level of $100 \mathrm{hPa}$ is $8 \%$ for water vapor and $0.7 \mathrm{~K}$ for temperature. Although MLS can retrieve atmospheric states in moderately cloudy conditions, line shape distortion caused by the strong scattering of thick clouds limits the retrieval capability (Livesey et al., 2017). Therefore, only data not affected by clouds, based on the status flag included with the product, are used to avoid degraded data quality. Moreover, due to the limb-viewing scanning geometry, MLS has a relatively large sampling footprint with a horizontal resolution of around $200 \mathrm{~km}$ along the track, which limits its sensitivity to smallscale variability (Schwartz et al., 2013).

AIRS measures infrared spectra from 650 to $2665 \mathrm{~cm}^{-1}$ with 2378 channels, using cross-track scans to provide large spatial coverage. Only the fields of view (FOVs) with viewing angles within $15^{\circ}$ of the nadir are used in this study, considering that the limb-view geometry increases the optical depth and the atmospheric attenuation. The selected viewing angle corresponds to a cross-track span of around $400 \mathrm{~km}$. The high spectral resolution in the mid-infrared makes AIRS sensitive to temperature, water vapor, and also clouds. However, the standard AIRS retrieval is not sensitive to the water vapor signal from the UTLS (Fetzer et al., 2008; Gettelman et al., 2004; Read et al., 2007) because of the weak absorption and/or emission of the dry UTLS relative to the troposphere and a cloud-clearing algorithm (Susskind et al., 2003) adopted by the AIRS standard retrieval. This algorithm infers temperature and trace gases of the clear-sky portion of adjacent $3 \times 3$ FOVs with varying cloud amounts by contrasting the nine FOVs, assuming a uniform distribution of these atmospheric states. Consequently, it degrades the horizontal resolution by a factor of 3 and suffers from large uncertainties when cloud amounts are uniform or when temperature and trace gases change drastically among the nine FOVs.

Therefore, instead of using the AIRS Level-2 product for above-cloud atmospheric conditions, we apply a synergistic, cloudy-sky retrieval method developed from the cloudassisted method proposed by Feng and Huang (2018). Targeting dense high-level clouds, this retrieval method retrieves water vapor, temperature, ice water content, and effective radius from the AIRS L1B product by combining active observations of mass concentration and the effective size of ice cloud particles from the DARDAR-Cloud product. This approach is hereafter referred to as either a joint AIRSDARDAR retrieval or a synergistic retrieval. While the information on temperature and water vapor profiles above clouds is obtained from spectrally dependent optical depths, the inclusion of active cloud observations substantially reduces uncertainties in cloud-top position and hence increases the sensitivity of the retrieval to the temperature and water vapor of topmost cloud layers. Using the wavenumber-dependent cloud extinction coefficients in the mid-infrared channels, this method marginally updates the concentration and effective particle size of ice clouds relative to the collocated cloud observations of active sensors. The effective radius is esti- 
mated as a vertically averaged value that produces the most reasonable mid-infrared emission spectra of thick high-level clouds (Feng et al., 2021). Through a simulation experiment, Feng et al. (2021) demonstrated that the synergistic method is sensitive to spatial variability in thermodynamic conditions above deep convection. Details of this retrieval method are presented in Appendix A. The retrieval achieves a precision of $0.31 \mathrm{~K}$ and $0.36 \mathrm{ppmv}$ for temperature and water vapor, respectively, as illustrated by Fig. A2. The vertical resolution at $100 \mathrm{hPa}$ is $3.2 \mathrm{~km}$ for temperature and $5.8 \mathrm{~km}$ for water vapor.

The impact of cyclones is assessed by calculating anomalies in cloud and non-cloud variables compared to their climatological values. In this paper, we define the climatology as the multi-year monthly mean of variables from 2006 to 2016, using IWC from DARDAR v2.1.1, temperature from AIRS L2 v6, water vapor from MLS v4.2, and brightness temperatures at 690 and $1231 \mathrm{~cm}^{-1}$ derived from AIRS L1B v5. All variables are assessed on a $1^{\circ} \times 1^{\circ}$ longitude-latitude grid unless specified otherwise.

\subsection{Compositing method}

In this study, a list of tropical cyclones observed by the ATrain satellites is obtained from the CloudSat tropical cyclone product (2D-TC; Tourville et al., 2015). This product uses best-track information provided from the Automated Tropical Cyclone Forecasting System (Tourville et al., 2015; Sampson and Schrader, 2000) to identify the cyclone center position. Note that only daytime measurements are available after 17 April 2011 due to a spacecraft battery issue. In addition to CloudSat, we combine CALIPSO, MLS, and AIRS together to provide the cloud distributions and atmospheric states associated with each cyclone overpass.

Measurements are composited relative to cyclone center locations in the northern part of the West Pacific region (the boxed region in Fig. 1a), given the abundance of data samples in this region. The density of measurement locations for each instrument is shown in Fig. 1. Samples from AIRS (Fig. 1d) are of a higher density compared to CloudSat (Fig. 1b) and MLS (Fig. 1c) owing to the advantage of the cross-track scanning of AIRS. Considering the differences in the sample densities and FOV sizes of the original measurements of these instruments, the cyclone-centered composites are constructed by averaging variables over different spatial scales - $60 \mathrm{~km}$ (CloudSat, as well as DARDAR which reports at CloudSat footprints), $120 \mathrm{~km}$ (MLS), and $20 \mathrm{~km}$ (AIRS) to ensure sufficient samples are obtained. Only observations collected over the ocean are used to avoid sample discrepancies arising from land-sea contrast. While both daytime and nighttime measurements are used, fewer nighttime measurements are available because of the daylight-only operation of CloudSat after 2011. Diurnal differences are noticeable in IWC profiles and the brightness temperature in the 20062011 period but are not addressed in study.

\section{Tropical cyclone impacts}

\subsection{Cloud distribution}

The datasets introduced earlier are used to depict the cloud distributions above cyclones. DCCs and TTL clouds are especially of interest here. TTL clouds, for the convenience of the analysis, are defined as cloud columns with one or more cloud layers above $16 \mathrm{~km}$, where the clear-sky LZRH and the mean tropopause (WMO, 1957) height are typically located in the tropics (Yang et al., 2010). These TTL clouds are further broken down into four categories to distinguish TTL clouds with or without underlying deep convective clouds. As shown by the schematic in Fig. 2, the four cloud categories are defined as follows:

- DCC-OT. This denotes deep convective clouds whose top boundary exceeds $16 \mathrm{~km}$.

- DCC-NOT. This denotes deep convective clouds whose top boundary is below $16 \mathrm{~km}$ while non-convective clouds are detected above $16 \mathrm{~km}$.

- CI. This denotes cirrus detected above $16 \mathrm{~km}$ and no DCC or any other cloud in the column.

- MIX. This denotes the remaining conditions (no DCC but cloud detected above $16 \mathrm{~km}$ ).

The DCC-OT category is used to identify continuous convective clouds that extend above $16 \mathrm{~km}$, which is the average altitude of the $380 \mathrm{~K}$ isentropic surfaces in the region of interest. These clouds are referred to as "overshooting" DCCs in the context of this paper. For convenience, TTL cloud categories without overshooting, including DCC-NOT, CI, and MIX, are also grouped as TTL-OTHER. Clouds with their top boundary below $16 \mathrm{~km}$ are referred to as NTTL.

As depicted by Fig. 2, cloud columns with DCCs are classified as either DCC-OT or DCC-NOT, where the former refers to overshooting DCCs and the latter refers to any other cloud types that contain DCCs in the column. The two categories are distinguished by whether the lowermost TTL clouds are connected with underlying DCCs because the adjacent clouds are essentially considered the same cloud type in the CloudSat 2B-CLDCLASS-LIDAR product. DCC-NOT typically consists of DCCs and cirrus with possible middle cloud layers between DCCs and cirrus. In the MIX category, TTL clouds may lie over either middle clouds (accounting for $90 \%$ of the MIX category) or low clouds ( $10 \%$ of the MIX category). Columns with only cirrus clouds are classified as CI. MIX and CI categories also include optically thick anvil clouds near the edge of DCCs because anvil cloud is classified as cirrus or altostratus in the 2B-CLDCLASS-LIDAR product (Wang et al., 2012; Young et al., 2013), depending on its vertical position.

The occurrence frequency of clouds and four cloud categories is then calculated as the ratio between the number 

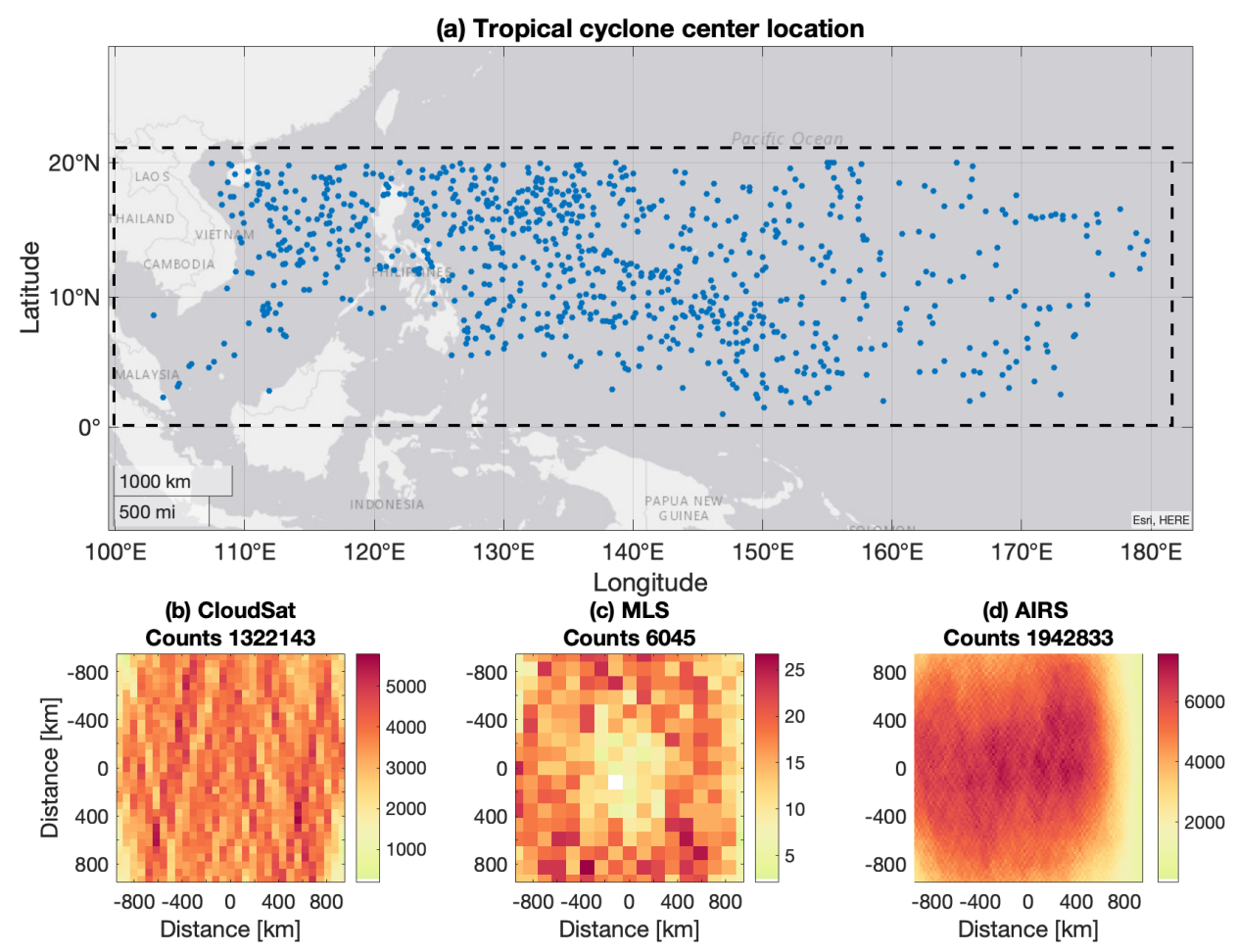

Figure 1. Distributions of cyclone centers passed over by A-Train and sample density from A-Train instruments with respect to cyclone center locations. (a) Locations of tropical cyclone centers (947 in total) that were passed over by the A-Train satellites from 2006 to 2016 over the northern part of the West Pacific region (within the boxed area). The sample density of (b) CloudSat (the DARDAR product is available at the horizontal footprints of CloudSat), (c) MLS, and (d) AIRS (limited to viewing angles within $15^{\circ}$ of the nadir) with respect to distances to cyclone center locations. The sample densities are defined as the number of samples per $100 \mathrm{~km} \times 100 \mathrm{~km}$ area, measured by normalizing sample counts within every $60 \mathrm{~km}(\mathbf{b}), 120 \mathrm{~km}(\mathbf{c})$, and $20 \mathrm{~km}(\mathbf{d})$ grid box over the area of the grid box. The numbers at the top of each panel show the total number of samples.

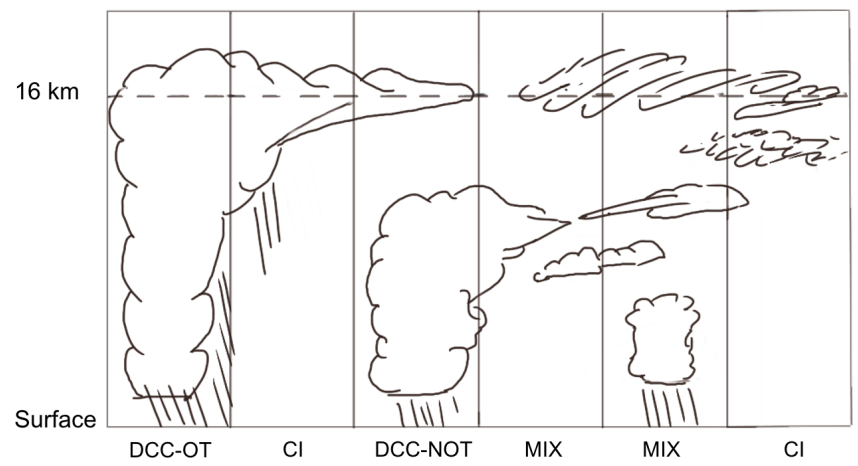

Figure 2. A schematic of the TTL cloud categories (see definitions in Sect. 3.1).

of samples with a certain feature, e.g., TTL clouds, and the number of overpass samples in each $60 \mathrm{~km} \times 60 \mathrm{~km}$ grid box in the cyclone-centered composite domain (Fig. 3a-b, d-g). Using IWC profiles from DARDAR-Cloud, a composite of ice water path (IWP) is derived in the same grid boxes. These results are also shown as a function of radial distance from the cyclone center in Fig. $4 \mathrm{a}-\mathrm{c}$.
Figures $3 \mathrm{a}$ and $4 \mathrm{a}$ show that TTL clouds occur frequently above tropical cyclones. In the $2000 \mathrm{~km} \times 2000 \mathrm{~km}$ cyclonecentered composite domain, TTL clouds have an occurrence frequency of 0.37 on average, which is significantly greater than the climatological value of 0.03 . This climatological value is derived from DARDAR-Cloud from 2006 to 2016, regardless of the presence of cyclones. DCCs occur mostly within $400 \mathrm{~km}$ of the cyclone center (Fig. 4a) and are noticeably more often on the southwest side of tropical cyclones (Fig. 3b). The occurrence frequency of DCCs in the composite domain is 0.1 on average, while the climatological value (regardless of cyclone condition) is only 0.008 . These results suggest that tropical cyclones considerably increase the occurrence frequencies of both DCCs and TTL clouds.

Figures $3 \mathrm{~d}-\mathrm{g}$ and $4 \mathrm{~b}$ break down the occurrence frequencies of different TTL cloud categories. They show that DCCOT tends to occur in the southwest quadrant within the $400 \mathrm{~km}$ radius. Outside the quadrant, the CI category has an occurrence frequency generally over 0.2 which makes up over $60 \%$ of the total TTL cloud occurrence. This suggests that the formation of high clouds is greatly promoted by tropical cyclone events, possibly by (1) transport of cloud ice 

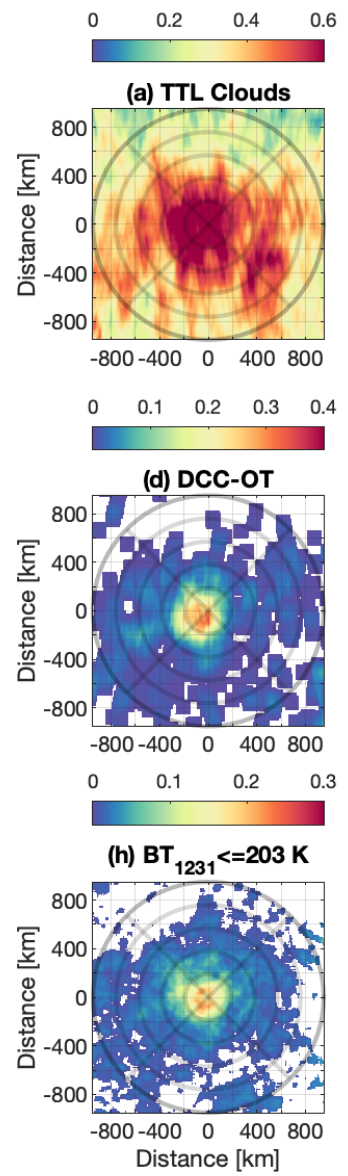

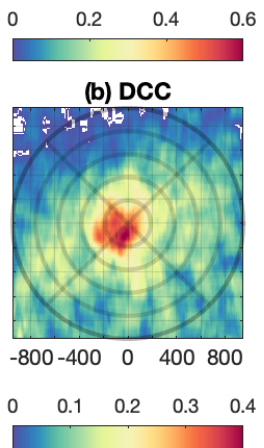

(e) DCC-NOT

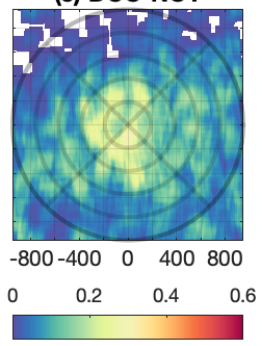

(i) $\mathrm{BT}_{1231}<=230 \mathrm{~K}$

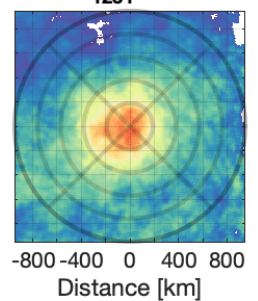

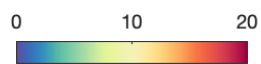
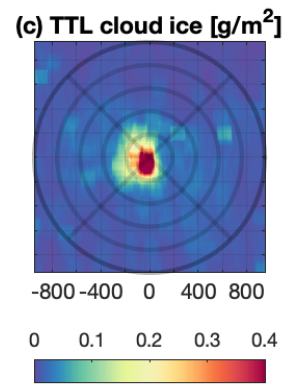

(f) $\mathrm{Cl}$

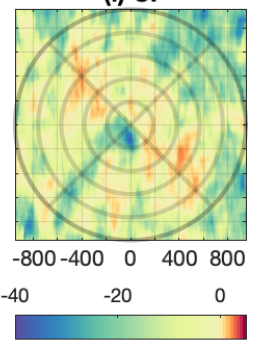

(j) $\mathrm{BT}_{1231}$ anomaly [K]

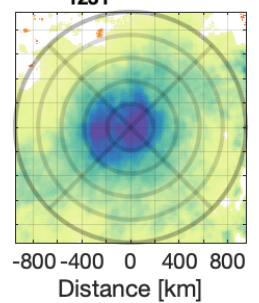

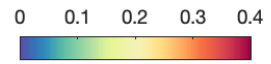

(g) MIX

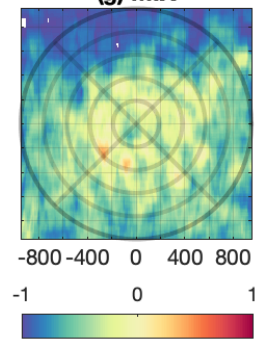

(k) $\mathrm{BT}_{690}$ anomaly [K]

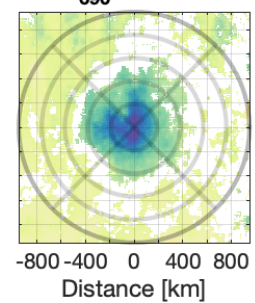

Figure 3. Cyclone-centered composite of cloud statistics. The occurrence frequency of (a) TTL clouds (i.e., clouds above $16 \mathrm{~km}$ ) and (b) deep convective clouds (regardless of TTL cloud occurrence). (c) Ice water path $\left(\mathrm{g} / \mathrm{m}^{2}\right)$ above $16 \mathrm{~km}$. The occurrence frequency of four TTL cloud categories (defined in Sect. 3.1 and schematically shown in Fig. 2): (d) DCC-OT (overshooting DCCs), (e) DCC-NOT (nonovershooting DCCs), (f) CI (cirrus), and (g) MIX (remaining conditions). The occurrence frequency of clouds identified by infrared radiance measurements: (h) deep convective clouds with $\mathrm{BT}_{1231} \leq 203 \mathrm{~K}$ and (i) overcast high clouds with $\mathrm{BT}_{1231} \leq 230 \mathrm{~K}$. Brightness temperature anomalies $(\mathrm{K})$ in $(\mathbf{j})$ an atmospheric window channel $\left(\mathrm{BT}_{1231}\right)$ and $(\mathbf{k})$ a $\mathrm{CO}_{2}$ channel $\left(\mathrm{BT}_{690}\right)$. Upper $(\mathbf{a}-\mathbf{c})$, middle $(\mathbf{d}-\mathbf{g})$, and lower $(\mathbf{h}-\mathbf{k})$ panels are based on data from DARDAR-Cloud-IWC, CloudSat 2B-CLDCLASS-LIDAR, and the AIRS L1B v5 product, respectively. Only statistically significant occurrence frequencies (at a $99 \%$ confidence level, compared to zero) are shown in (a, b, d-i), and only significant brightness temperature anomalies (99\%, compared to the climatology) are shown in (j, k).

via convective outflow from cyclone centers and propagating waves and (2) local cooling that condensates supersaturated water vapor into ice (Tseng and Fu, 2017; Schoeberl et al., 2019) as a result of dynamical and radiative cooling which is discussed in Sects. 3.3.1 and 4.

In contrast to the uniformly distributed TTL cloud (Fig. 3a), Fig. 3c shows that the TTL cloud ice is concentrated in regions closest (within $200 \mathrm{~km}$ ) to the cyclone center, most often to the southwest, similarly to the DCC-OT (Fig. 3d). This coincidence suggests potential contributions from DCCs that penetrate $16 \mathrm{~km}$ (DCC-OT) to TTL cloud ice. Hence, we calculate the fractional contribution to TTL cloud ice from each TTL cloud category, defined as the ratio between the sum of TTL cloud ice of one cloud category and the total TTL cloud ice. Figure $4 \mathrm{c}$ confirms that DCC-OT clouds account for over $80 \%$ of TTL cloud ice near the cyclone center. After integrating over the area within $1000 \mathrm{~km}$ of cyclone centers, DCC-OT clouds account for $43 \%$ of the cloud ice with only $5 \%$ of the observed TTL cloud cover, while CI accounts for $23 \%$ of the cloud ice with $48 \%$ of the observed TTL cloud cover. Overall, Figs. 3 and 4 suggest that most TTL clouds above cyclones are cirrus above a clear troposphere (CI), while the TTL cloud ice is largely contained by overshooting deep convective clouds (DCC-OT).

\subsection{Infrared radiance}

In the previous section, the distribution patterns of clouds above tropical cyclones were analyzed by combining observational products from CloudSat and CALIPSO. Compared with the nadir-view-only instruments, AIRS provides 

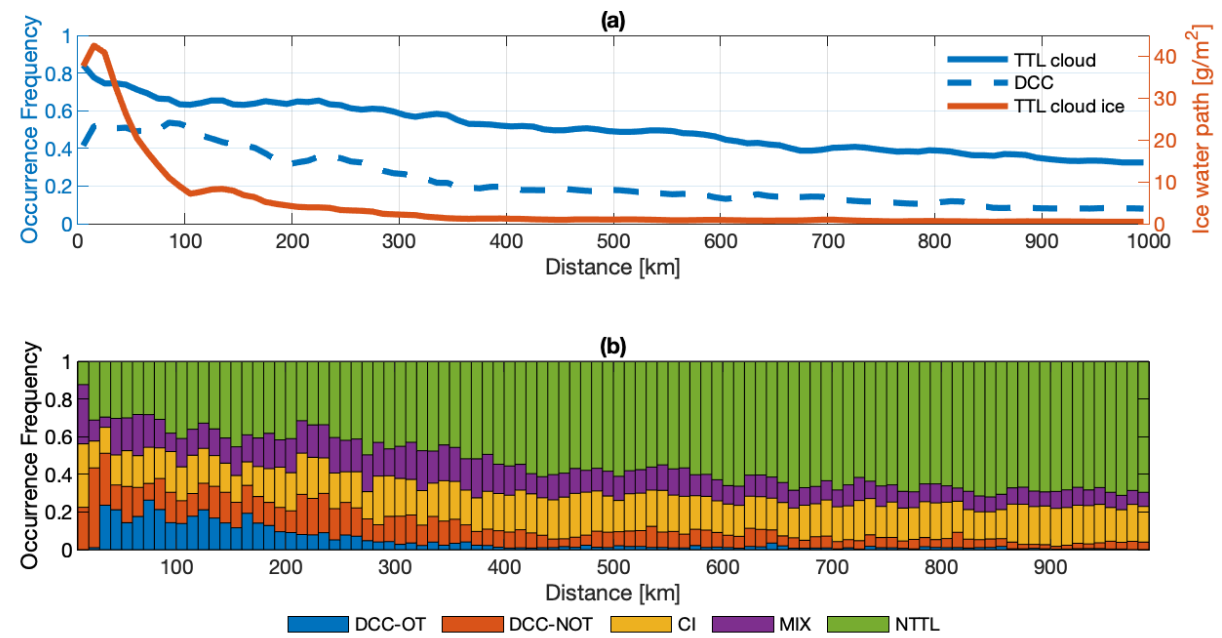

(c)

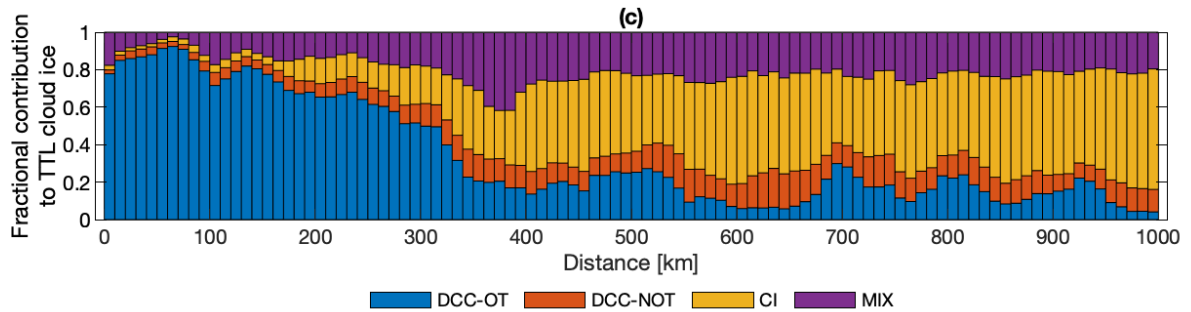

(d)

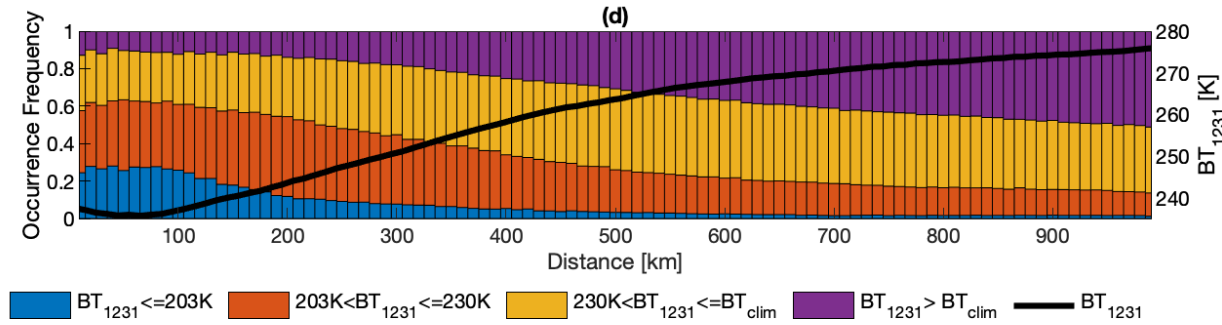

Figure 4. Cloud statistics as a function of radial distance to the cyclone center. (a) Occurrence frequency of TTL clouds (solid blue curve) and deep convective clouds (dashed blue curve); the red curve is the ice water path $\left(\mathrm{g} / \mathrm{m}^{2}\right)$ above $16 \mathrm{~km}$. (b) Occurrence frequency of each cloud category (schematically shown in Fig. 2). (c) Fractional contribution to the TTL cloud ice (the red curve in panel a) by each cloud category. (d) Occurrence frequencies of clouds classified by $\mathrm{BT}_{1231}$. $\mathrm{BT}_{\text {clim }}$ refers to the multi-year monthly mean $\mathrm{BT}_{1231}$. The black curve shows the average $\mathrm{BT}_{1231}$.

expanded spatial coverage by performing a cross-track scan. With over 2000 channels, this hyperspectral instrument can profile atmospheric absorbers and temperatures. For example, the brightness temperature (BT) in the atmospheric window channel is a measure of cloud thermal emission temperature which is useful for inferring cloud-top height.

As described in Sect. 3.1, the overshooting DCC is a major source of TTL cloud ice. The spectral signatures of the overshooting DCCs are further investigated. Previous studies (Aumann et al., 2011; Aumann and Ruzmaikin, 2013) have shown that overshooting DCCs are identifiable by cold BT anomalies in the window channels, e.g., at the $1231 \mathrm{~cm}^{-1}$ channel ( $\left.\mathrm{BT}_{1231}\right)$, and also positive $\mathrm{BT}$ differences between the water vapor and window channels $\left(\triangle \mathrm{BT}=\mathrm{BT}_{1419}-\right.$ $\mathrm{BT}_{1231}$ ) (Aumann et al., 2011; Aumann and Ruzmaikin, 2013). The cold $\mathrm{BT}_{1231}$ is a result of the extremely high vertical reach (and thus the very low cloud-top temperature) of the DCCs; the positive $\triangle \mathrm{BT}$ indicates emission from warm stratospheric layers against the cold cloud top. However, there is no consensus on the threshold values of these quantities to identify DCCs, partly because of uncertainty in the temperature distribution above DCCs due to the impacts of convection. Following the statistical analysis detailed in Appendix B, we find the optimal threshold for identifying overshooting DCCs to be $\mathrm{BT}_{1231} \leq 203 \mathrm{~K}$, corresponding to a false positive rate of 0.008 and a false negative rate of 0.323 . We find that incorporating $\triangle \mathrm{BT}$ does not improve the detection.

This $\mathrm{BT}_{1231} \leq 203 \mathrm{~K}$ criterion is then applied to AIRS overpass measurements (Fig. 1d). Figure $3 \mathrm{~h}$ shows that the deep convective clouds identified by this criterion are distributed similarly to the overshooting DCCs (DCC-OT) clas- 
sified by CloudSat. It also confirms that overshooting DCCs are most likely to occur in the southwest quadrant.

Similarly, a $\mathrm{BT}_{1231} \leq 230 \mathrm{~K}$ criterion is used to identify thick upper tropospheric clouds. This criterion detects cloud tops above $11 \mathrm{~km}$, which corresponds to a climatological mean temperature of $230 \mathrm{~K}$. The identified upper tropospheric clouds are distributed mainly within the $400 \mathrm{~km}$ radius, as depicted in Fig. 3i, with a frequency of more than 0.3 . Figure $3 \mathrm{i}$ also reveals fewer thick high clouds on the northwestern quadrant of the domain, which is similar to the results based on CloudSat data (Fig. 3e, g). This $\mathrm{BT}_{1231}$ criterion is also used for identifying FOVs with thick upper tropospheric clouds to perform the synergistic retrieval method discussed in Sect. 3.3.

For each AIRS overpass sample, the $\mathrm{BT}_{1231}$ anomaly is calculated as the deviation from the climatology. As shown in Fig. 3 j, cyclones induce a significant cold anomaly in $\mathrm{BT}_{1231}$ over the composite domain.

The reduced window channel radiance $\left(\mathrm{BT}_{1231}\right)$ suggests that cyclone clouds effectively attenuate infrared radiation emitted from the surface, thus potentially leading to a net radiative cooling of the atmospheric layers above the clouds. Hence, it is interesting to examine whether tropical cyclones leave detectable signatures in the temperature fields. A composite of $\mathrm{BT}$ anomalies using a $\mathrm{CO}_{2}$ absorption channel $\left(690 \mathrm{~cm}^{-1}\right)$ is shown in Fig. 3k. This channel has a weighting function that peaks at $85 \mathrm{hPa}$ and is thus sensitive to the cold-point temperatures (i.e., the vertical temperature minima) that climatologically occur near this level. Indeed, Fig. 3k shows a cold $\mathrm{BT}_{690}$ anomaly above cyclones, especially around the cyclone center. However, we cannot eliminate the possible impacts of cloud emission, which will be addressed in the following section using different methods, including a synergistic retrieval that we have developed for application to A-Train data.

\subsection{Temperature and water vapor}

In the previous sections, we found substantial increases in cloud occurrence and cloud ice above tropical cyclones. Previous studies (Ueyama et al., 2018; Schoeberl et al., 2018) have suggested that injection of TTL cloud ice can lead to either hydration or dehydration depending on the pre-existing conditions. Hence, it is important to examine the water vapor field above tropical cyclones to ascertain both the sign and the magnitude of the (de)hydration impact.

A joint AIRS-DARDAR retrieval method has been developed to retrieve atmospheric conditions above thick upper tropospheric clouds, combining hyperspectral infrared radiances from AIRS and collocated IWC profiles from DARDAR-Cloud. The retrieval method was described in detail and validated using a simulation experiment in Feng et al. (2021). Additional information is provided in Appendix A to explain how the temperature and water vapor above tropical deep convection are retrieved.
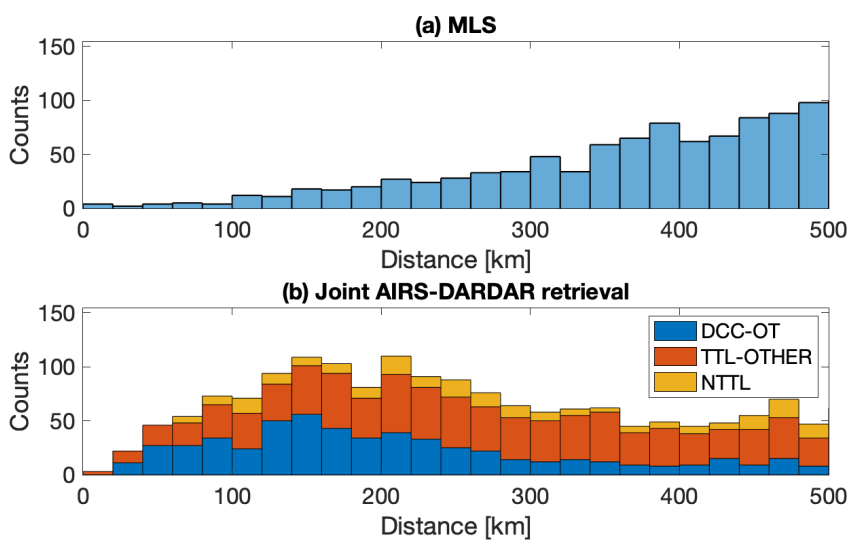

Figure 5. Sample densities used for assessing temperature and humidity distributions from (a) MLS and (b) the joint AIRSDARDAR retrieval.

The AIRS FOVs selected for the synergistic retrieval are within $6.75 \mathrm{~km}$ (half of the AIRS nadir footprint size) of the nearest DARDAR cloud profile and have window band brightness temperatures $\left(\mathrm{BT}_{1231}\right)$ colder than $230 \mathrm{~K}$. The $\mathrm{BT}_{1231}$ threshold ensures that liquid clouds can be neglected in the retrieval. The frequency of AIRS FOVs passing this criterion is shown in Figs. 3i and 4d. The selection of FOVs is illustrated in Fig. 6 for a tropical cyclone event. In this figure, the brightness temperature in a window channel from AIRS L1B observation depicts a typical cyclonic cloud distribution. The vertical cross-section illustrates the retrieval over selected AIRS FOVs. The same data selection and retrieval processes are performed for all tropical cyclone overpasses. In total, 3475 FOVs from 345 tropical cyclone events are selected, with 2735 profiles successfully retrieved (reaching convergence in the iterative retrieval procedure). The converged retrievals are mostly located within $500 \mathrm{~km}$ of the cyclone center; their distributions are shown in Fig. 5b. A total of 740 FOVs do not converge and are not used for further analysis. These FOVs typically have large radiance residuals between AIRS observations and the forward model calculations, where cloud states from DARDAR-Cloud and prior atmospheric states are used as inputs. Possible causes of nonconvergences include (1) non-uniform cloud cover among the FOVs so that the $1.4 \mathrm{~km} \times 1.8 \mathrm{~km}$ CloudSat footprints are not representative of the $13.5 \mathrm{~km} \times 13.5 \mathrm{~km}$ AIRS FOVs and (2) the optical thickness of the topmost cloud layer being smaller than 1 so that the assumption of vertically uniform optical properties per cloud mass does not hold in the radiative transfer calculations (Feng et al., 2021). The retrieved temperature, water vapor, and clouds are shown as a function of vertical level and radial distance in Fig. 7a, e.

Owing to smaller horizontal sampling footprints and the availability of collocated cloud observations, the synergistic retrieval can reveal relatively small-scale variations in the thermodynamic fields above TTL clouds. To understand 

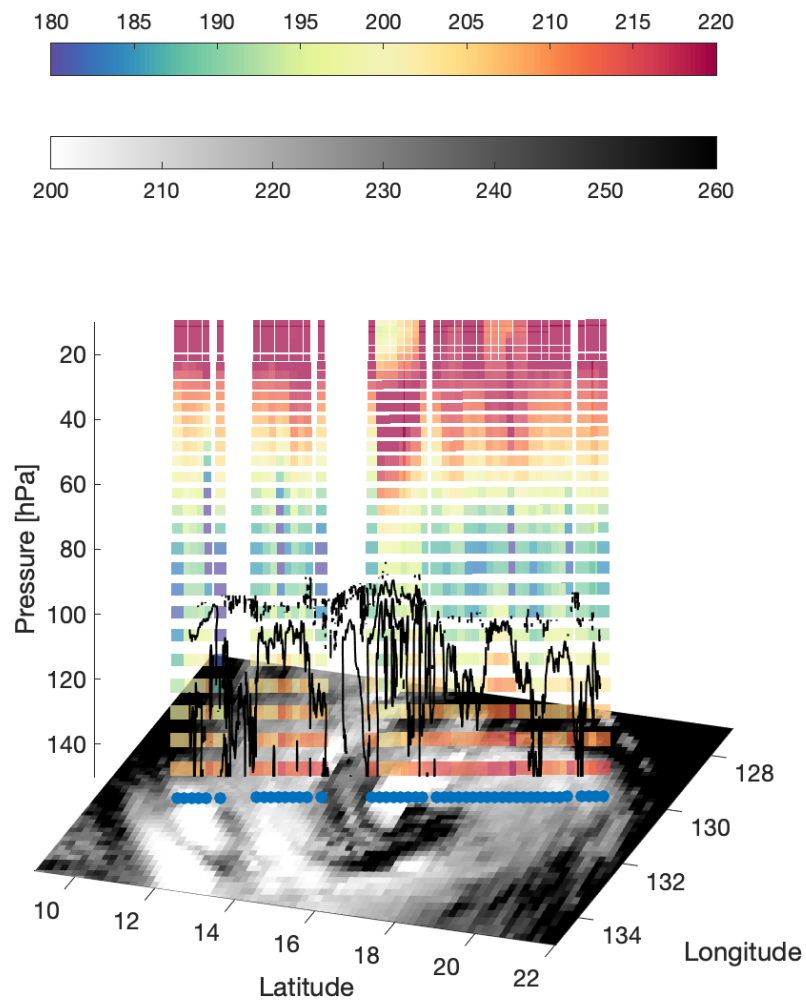

Figure 6. A-Train overpass and retrievals of a tropical cyclone event on 2 October 2007. The underlying image in greyscale shows the brightness temperature in a window channel ( $\mathrm{BT}_{1231}$, in $\left.\mathrm{K}\right)$ from the AIRS L1B product and indicates the cloud-top temperature. The vertical cross-section in color contours illustrates the temperature (K) retrieval over thick upper tropospheric clouds $\left(\mathrm{BT}_{1231}\right.$ colder than $230 \mathrm{~K}$ ) using the synergistic method described in the text; the black line marks the IWC at $10^{-4} \mathrm{~g} / \mathrm{m}^{3}$ based on the DARDAR data and outlines the cloud-top positions.

whether overshooting convection has a direct impact on water vapor, retrieved samples are classified into overshooting DCCs (DCC-OT), non-overshooting TTL clouds (TTLOTHER), and non-TTL clouds (NTTL), using the same cloud classification as that introduced in Sect. 3.1 and Fig. 2. The converged profiles contain 731 clouds of the category DCC-OT, 1508 of TTL-OTHER, and 496 of NTTL; the sample counts are shown in Fig. 5b. The mean profiles for each category are shown in Fig. 9a and b. These samples are representative of the cloud categories but may not be representative of the geographical pattern associated with tropical cyclone events because the number of samples within each radius bin is limited.

Meanwhile, similar cyclone-centered composites of thermodynamic fields are constructed using MLS v4.2 and ERA5 (Hersbach et al., 2020) in Fig. 7. The sample locations of ERA5 are identical to the measurement locations used for the joint AIRS-DARDAR retrieval. The measurement locations of MLS products used in this study are shown in Figs. 1c and 5a. The sample density of MLS near the cyclone cen- ter is lower because only measurements not affected by high clouds are used. Figure 7 also shows composites of IWC from the synergistic retrieval (Fig. 7a, e), from DARDARCloud (Fig. 7b, f) corresponding to measurements shown in Fig. 1b) and from ERA5 (Fig. 7c, g) at retrieved sample locations. We note that there is no collocation between CloudSatCALIPSO (DARDAR) and MLS in Fig. 7b and $\mathrm{f}$ as only MLS observations not impacted by high clouds are selected.

The effects of cyclones on temperature and water vapor are examined by subtracting the multi-year monthly mean at every sample location from Fig. 7. The anomalous thermodynamic fields are presented in Fig. 8, while the mean anomalies for the three cloud categories (DCC-OT, TTL-OTHER, and NTTL) are shown in Fig. 9c and d. For MLS and ERA5, the monthly mean climatologies are constructed using the same dataset (MLS or ERA5, respectively). For the synergistic retrieval, there is no available "climatology" from this retrieval dataset for non-cyclonic conditions. AIRS L2 temperature and MLS water vapor products are used instead, which are converted to the same vertical resolution to reduce systematic bias, as described in Appendix A.

\subsubsection{Temperature}

Using the synergistic retrieval, we find that tropical cyclone events lead to an oscillating pattern of temperature anomalies above the cloud top (Fig. 8a). This pattern shifts the cold-point tropopause to higher altitudes (see also Fig. 9a). Compared with the climatology, the mean temperature profile above cyclones shows a noticeable negative anomaly between 40 and $100 \mathrm{hPa}$ and positive anomalies at other vertical ranges. We note that this cold anomaly at around $80 \mathrm{hPa}$ also supports the cold signature in $\mathrm{BT}_{690}$ displayed in Fig. $3 \mathrm{k}$. This vertically oscillating anomaly feature is consistent with previous findings using radiosonde and GPS radio occultation measurements (Holloway and Neelin, 2007; Biondi et al., 2013; Rivoire et al., 2016).

The oscillating pattern of temperature anomalies may arise for a few reasons. The good alignment of the cold anomaly with the cloud-top position around the cold point $(\sim 80 \mathrm{hPa})$ implicates the impact of cloud radiative effects. This motivates us to ascertain the role of radiation in forming the retrieved temperature pattern. The thick cloud layers may absorb incoming solar radiation to heat the cloud top while attenuating emission from the warm surface to cool the atmospheric layers above the cloud. These expected cloud radiative effects agree with the signs of temperature anomalies and will be further examined in Sect. 5. On the other hand, Rivoire et al. (2020) pointed out that cloud radiative cooling only partly explains the cooling tendency above tropical cyclones. Other mechanisms at play may include the adiabatic expansion (Holloway and Neelin, 2007) in convective overshoots (Robinson and Sherwood, 2006) and the outward branches of secondary circulation (Rivoire et al., 2020; Schubert and McNoldy, 2010). 

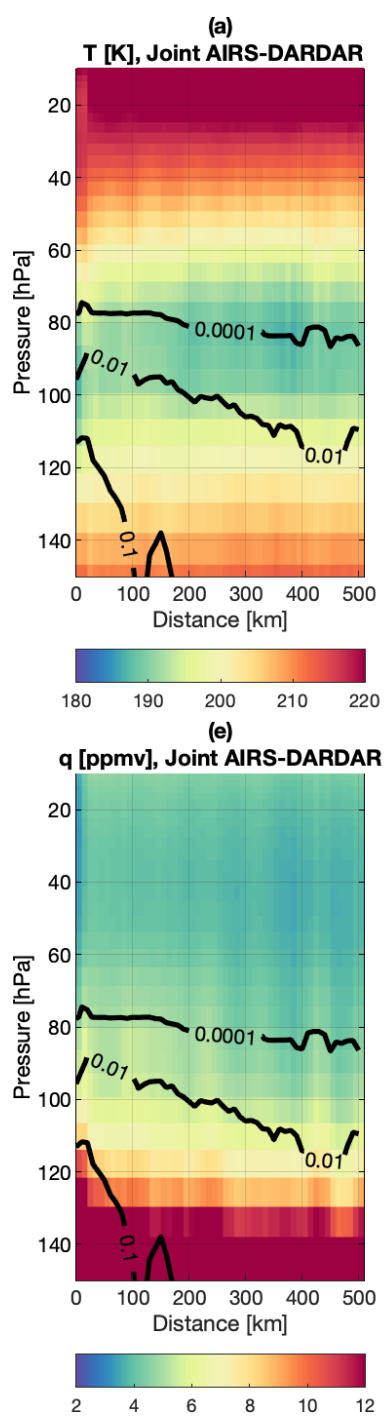

(b)

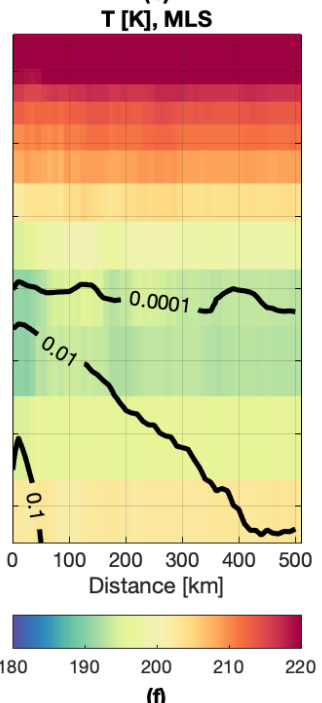

q [ppmv], MLS

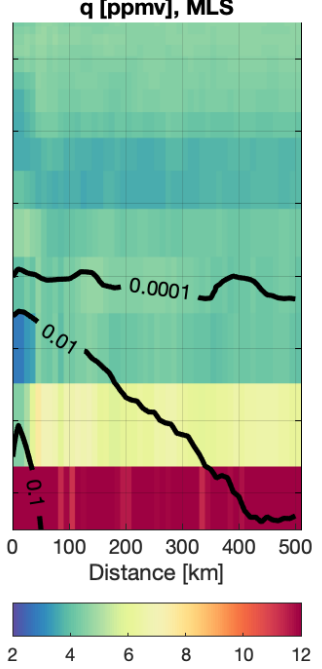

(c)

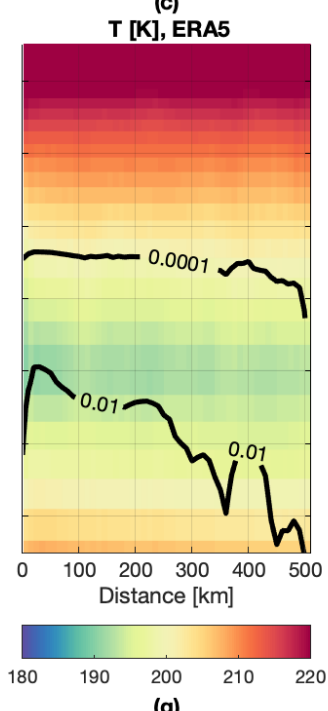

q [ppmv], ERA5

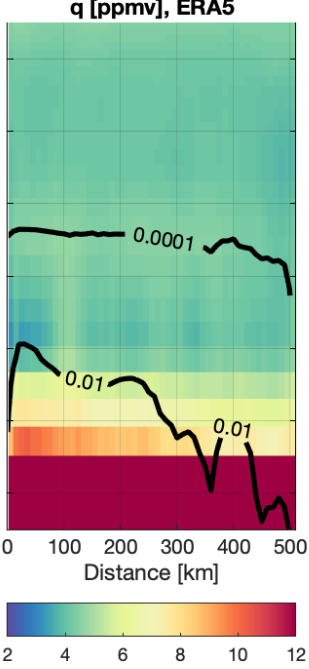

(d) Mean T [K]

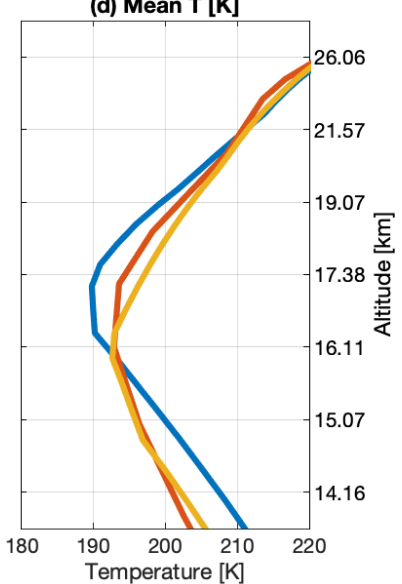

(h) Mean q [ppmv]

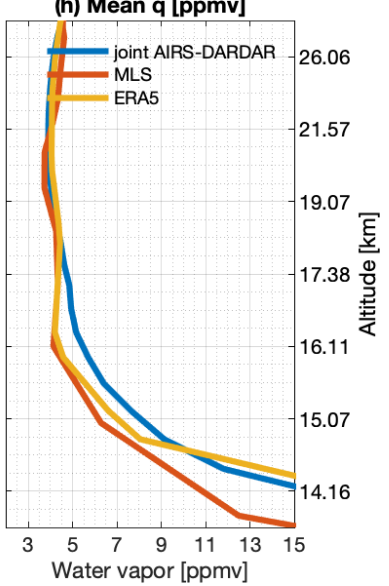

Figure 7. Cyclone-centered composites of temperature (shading, K), water vapor (shading, ppmv), and ice water content (black contour, $\mathrm{g} / \mathrm{m}^{3}$ ). Temperature (a) and water vapor (e) from the joint AIRS-DARDAR retrieval; the sample counts are shown in Fig. 5b. Temperature (b) and water vapor (f) from the MLS v4.2 product; the sample counts are shown in Figs. 1c and 5a. The IWC is from DARDAR-Cloud; the sample density is shown in Fig. 1a. Temperature (c) and water vapor (g) from the ERA5 product sampled at the same locations as in (a, e). Mean temperature (d) and water vapor (h) profiles from the different datasets.

It is also interesting to find that the temperature anomaly is stronger above non-overshooting clouds (TTL-OTHER) than over DCC-OT or NTTL (Fig. 9a, c). This finding suggests a potential linkage between the temperature anomaly and the formation of TTL clouds. For example, one plausible explanation is that the cooling of air above cyclones promotes the formation of thicker TTL clouds by favoring water vapor deposition onto ice particles, as seen in Figs. 9d and 10 and discussed in Sect. 3.3.2.

We note that the significant temperature anomaly pattern identified by the synergistic retrieval is not found in either MLS or ERA5. Livesey et al. (2017) have documented that MLS temperature retrievals are particularly susceptible to cloud contamination, while Schwartz et al. (2008) note that this issue cannot be effectively screened out by the status flag of the MLS product. Therefore, the MLS temperature product may not be able to observe the pattern of temperature anomaly.

By comparing ERA5 (Figs. 7c and 8c) to the synergistic retrieval (Figs. 7a and 8a), we find that although ERA5 produces a higher cloud top (marked by $10^{-4} \mathrm{~g} / \mathrm{m}^{3}$ IWC contour) than the DARDAR observation, it generally underestimates TTL cloud ice. ERA5 also exhibits a cold anomaly but places it at lower altitudes compared to the synergistic retrieval, which is partly attributable to different radiative heating signatures due to differences in cloud ice. Previous 
(a)
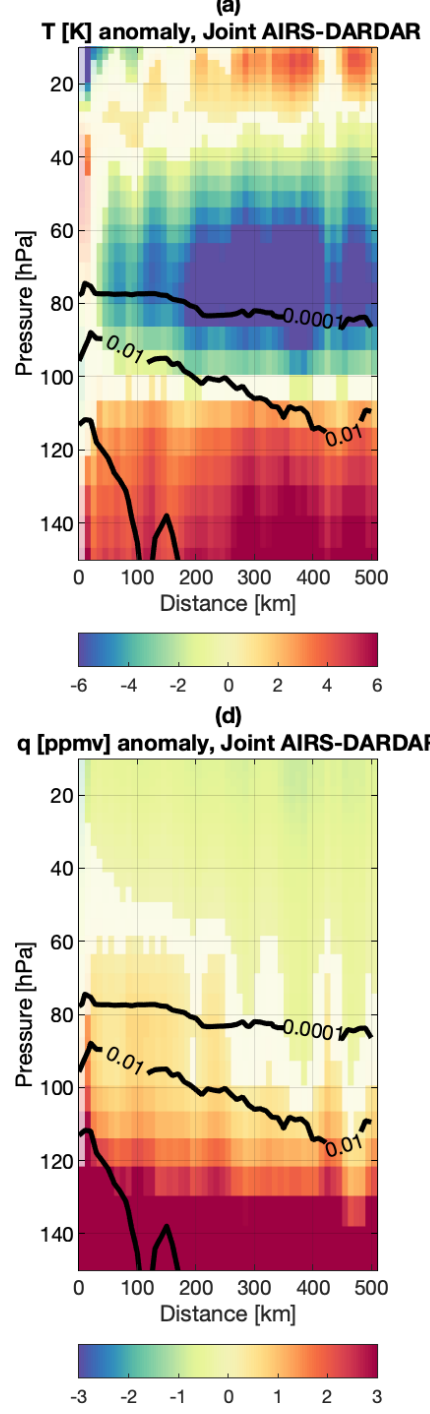

(b)
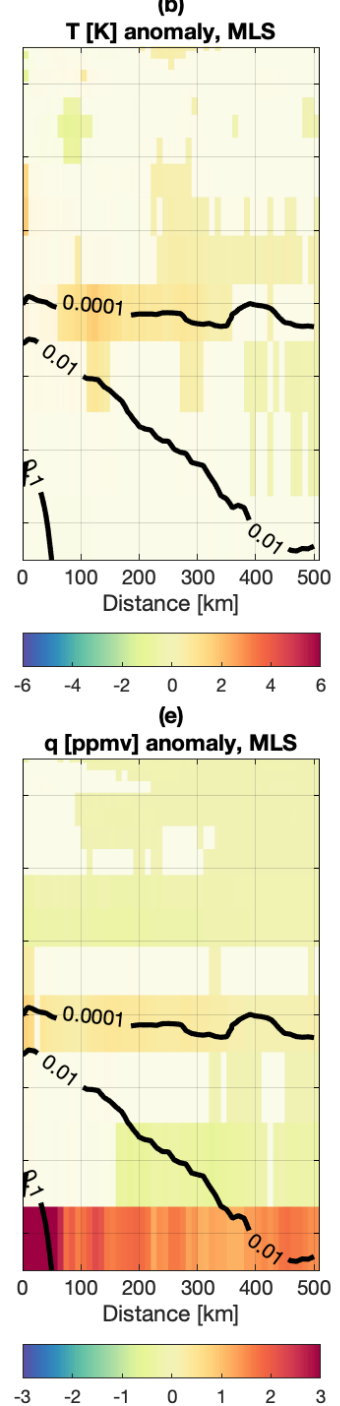

(c)
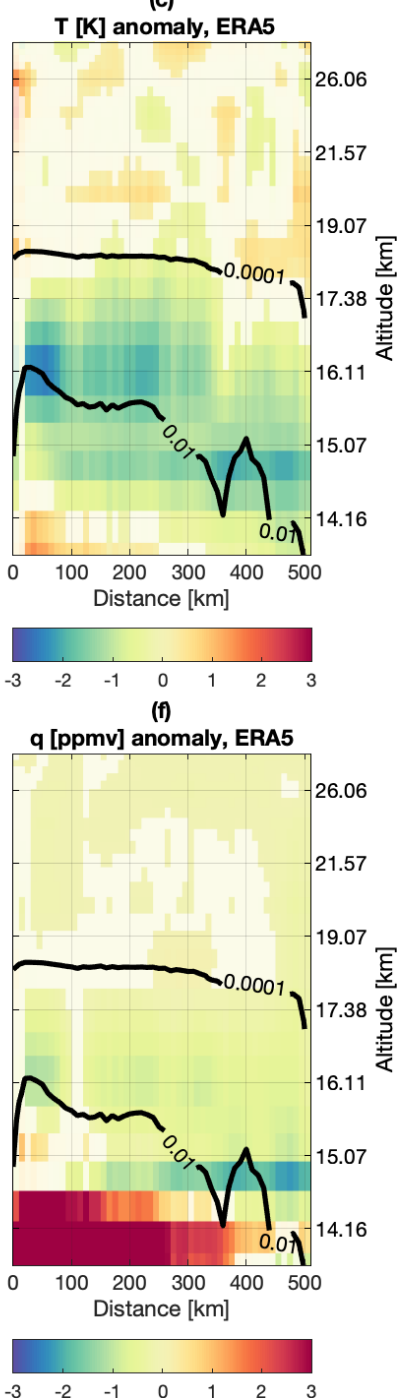

Figure 8. Cyclone-centered composites of temperature (shading, K), water vapor anomalies (shading, ppmv), and ice water content (black contour, $\mathrm{g} / \mathrm{m}^{3}$ ). Anomalies below the $99 \%$ confidence level are set to be transparent. (a, d) Similar to Fig. 7a and e but after subtracting the climatologies of temperature from the AIRS L2 product and water vapor from the MLS v4.2 product, respectively. (b, e) Similar to Fig. 7b and $f$ but after subtracting the climatologies of temperature and water vapor from the MLS v4.2 product. (c, f) Similar to Fig. 7c and g but after subtracting the climatologies of temperature and water vapor from ERA5.

studies (Wright et al., 2020) have also found large discrepancies in the upper tropospheric temperature and tropical high clouds among reanalysis products, likely due to convective parameterization (Takahashi et al., 2016; Wright et al., 2020).

\subsubsection{Water vapor}

Using the synergistic retrieval, Fig. 8d shows that both hydration and dehydration can occur above cyclones. Hydration is found below $80 \mathrm{hPa}$, especially near the cyclone center, while dehydration is found above $60 \mathrm{hPa}$. This finding is consistent with MLS observations (Fig. 8e), even though the synergistic retrievals are performed above thick upper tropospheric clouds while the selected MLS observations are high-cloudfree.

We note that the synergistic retrieval does not have sufficient vertical sensitivity to fully resolve the vertical distribution of water vapor due to the smearing effect of the averaging kernel discussed in Appendix A. Nevertheless, the retrieval is sensitive to the spatial variability in the layer integrated water vapor above $16 \mathrm{~km}$ (LIWV), which has been validated by Feng et al. (2021) and in Appendix A. The retrieved LIWV above $16 \mathrm{~km}$ is shown in Fig. 10a and $\mathrm{b}$ as a function of radial distance from the cyclone center. Therefore, we focus on the horizontal variability in LIWV above cyclones, which can be more confidently detected by the syn- 

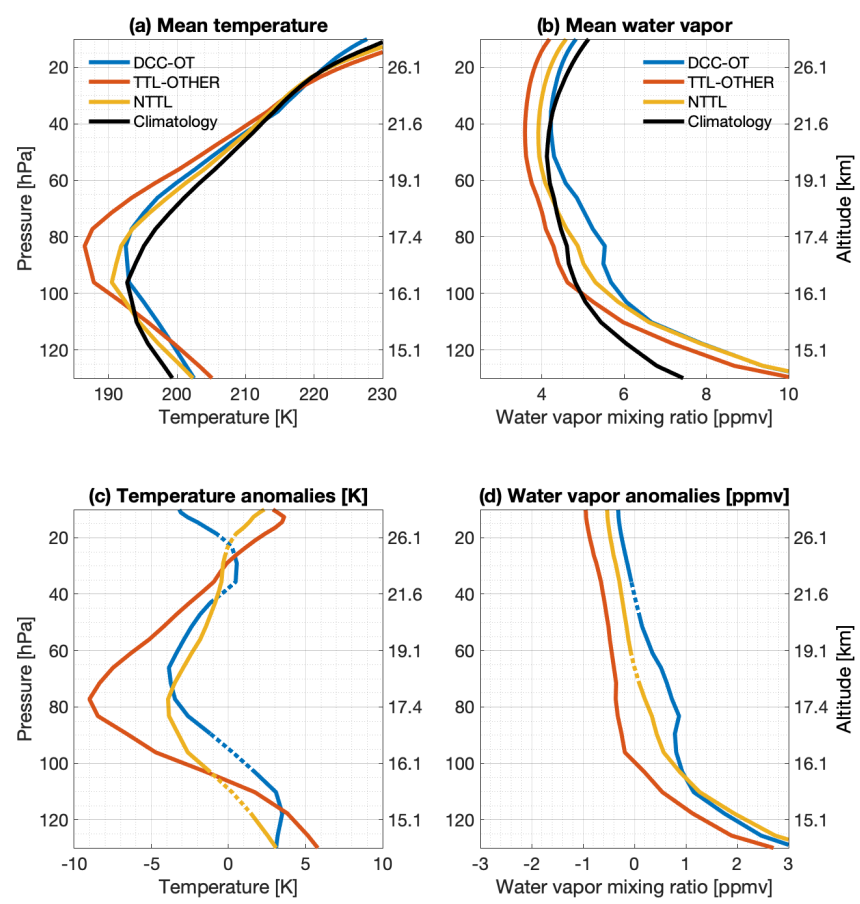

Figure 9. The mean (a) temperature $(\mathrm{K})$ and (b) water vapor (ppmv) profiles above cyclones, for overshooting TTL clouds (DCC-OT, blue), non-overshooting TTL clouds (TTL-OTHER, orange), and non-TTL clouds (NTTL, yellow), along with the climatology (black). (c, d) The same as (a, b) but for anomalies with respect to the climatology.

ergistic retrieval, to disclose overall hydration or dehydration above $16 \mathrm{~km}$.

The synergistic retrieval detects a decreasing LIWV with increasing radial distance (Fig. 10a, b). Significant hydration occurs near the cyclone center, increasing the LIWV by up to $0.18 \mathrm{~g} / \mathrm{m}^{2}(\sim 9 \%)$, while dehydration occurs at around a distance of $375 \mathrm{~km}$. In MLS, the LIWV does not substantially differ from the climatology, possibly because MLS samples large, high-cloud-free areas.

The (de)hydration impact of cyclones is classified after isolating DCC-OT, TTL-OTHER, and NTTL clouds. As depicted in Fig. 10a and b, significant dehydration is found above only non-overshooting TTL clouds, while significant hydration is found above overshooting clouds and non-TTL clouds. DCC-OT clouds increase the LIWV above $16 \mathrm{~km}$ by up to $0.4 \mathrm{~g} / \mathrm{m}^{2}$, which is equivalent to $20 \%$ of the climatological value. This suggests that overall the air above cyclones is hydrated by convection, especially overshooting convection that penetrates the base of the TTL. The non-overshooting TTL clouds (TTL-OTHER), however, are found to be associated with a drier environment, possibly due to the deposition of water vapor onto ice particles in colder temperatures (as suggested by Figs. 8a and 9a, c).

The occurrence frequency of thick upper tropospheric clouds (AIRS FOVs being colder than $230 \mathrm{~K}$ ), above which
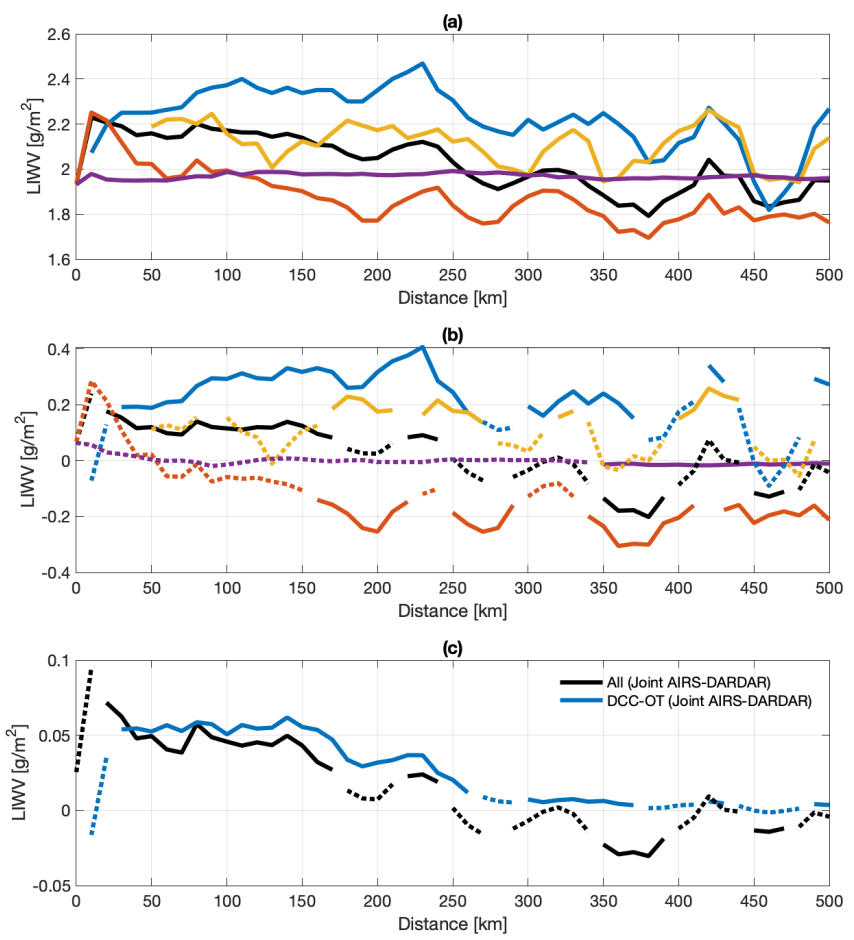

- All, (Joint AIRS-DARDAR) - DCC-OT(

Figure 10. (a) Layer integrated water vapor (LIWV) above $16 \mathrm{~km}$ from the joint AIRS-DARDAR retrieval (black) and MLS (purple). Samples retrieved by the synergistic retrieval are separated into overshooting TTL clouds (DCC-OT, blue), other non-overshooting TTL clouds (orange), and non-TTL clouds (yellow). Solid curves show the statistically significant (99\% confidence level) anomalies, while dashed curves are not statistically significant at the $99 \%$ level. (b) The same as (a) except for the anomaly in LIWV. (c) Contributions to the LIWV anomaly from thick upper tropospheric clouds $\left(\mathrm{BT}_{1231}<230 \mathrm{~K}\right.$, black) and DCC-OT clouds (blue).

the synergistic retrieval is conducted, is shown in Fig. 4d. The expectation of changes in LIWV contributed by thick upper tropospheric clouds is then estimated by multiplying the LIWV anomaly (Fig. 10b) by the occurrence frequency of these clouds (Fig. 4d, blue and orange areas). Figure 10c shows that the LIWV above cyclones is expected to be around $0.05 \mathrm{~g} / \mathrm{m}^{2}(1.5 \%)$ larger than the climatology within a $150 \mathrm{~km}$ radius of the cyclone center and to be as much as $0.03 \mathrm{~g} / \mathrm{m}^{2}(0.9 \%)$ smaller at a distance of $375 \mathrm{~km}$. On average, the stratospheric column above thick upper tropospheric clouds within $500 \mathrm{~km}$ of cyclone centers is $0.014 \mathrm{~g} / \mathrm{m}^{2}$ moister than the climatology. A similar calculation is performed for DCC-OT clouds, using the occurrence frequency of DCC-OT clouds shown by the blue area in Fig. 4b. It is found that DCC-OT alone increases the mean LIWV above tropical cyclones by $0.024 \mathrm{~g} / \mathrm{m}^{2}$, which is around $0.7 \%$ of the climatological value.

In summary, hydration is found to result from overshooting convection, which injects water substances directly. The 
moisture injected by overshoots hydrates the surrounding environment so that the cloud-free TTL (NTTL) also shows higher LIWV compared to the climatology. However, at locations away from overshoots, we find that overflow or preexisting clouds in the TTL are associated with a colder and drier environment, potentially due to water vapor deposition onto ice particles.

\section{Radiative effects}

In the context of this paper, we have defined the lower boundary of the TTL to be the clear-sky level of zero radiative heating (LZRH). Radiative heating rates in the TTL are crucial, for instance, to the cross-tropopause transport of water vapor as they potentially drive the diabatic ascent of air parcels across isentropic surfaces to the stratosphere. While the ascending motion that prevails in the tropical lower stratosphere is driven by dissipating waves (Holton et al., 1995; Plumb, 2002), it is found that TTL clouds can heat the air through infrared radiation and are important for explaining the mass flux to the stratosphere (Corti et al., 2006; Yang et al., 2010). Hence, we are interested in how radiative heating rates are perturbed above tropical cyclones and whether this helps retain the moisture anomaly in the TTL.

Moreover, as indicated by the close alignment of cloud boundary and temperature anomalies, cloud radiative effects may have played a role in forming the temperature anomalies seen in Fig. 8. Therefore, a cyclone-centered composite of radiative heating rates is constructed using the CloudSat 2B-FLXHR-LIDAR product to help address these questions.

The cloud radiative effect, measured by the radiative heating rate difference between all-sky and clear-sky overpasses, is shown as a function of the pressure level and radial distance from the cyclone center in Fig. 11c and d. Only daytime samples (overpasses at 13:30 local solar time) are used to exclude the lack of shortwave heating during the nighttime. We identify the LZRH in the heating rate profiles as the level where heating rates change from negative to positive. Note that there is no LZRH identified in two conditions: in Fig. 11a and $\mathrm{c}$ when the longwave heating rate is entirely negative in the TTL and in Fig. 11b, d, and e when the net heating rate is entirely positive.

In the longwave spectrum, Fig. 11c shows that clouds generally produce positive perturbations inside the clouds (below $200 \mathrm{hPa}$ ) but strong cooling at the atmosphere near and above the cloud top (marked by the $0.01 \mathrm{~g} / \mathrm{m}^{3}$ IWC contour). Figure 11d shows that this cloud-top longwave cooling effect is offset by the shortwave effect. The compensation between longwave and shortwave effects leads to a net cloud radiative cooling effect in the layers above the cloud top but a net cloud radiative heating effect below the cloud top. These effects shift the clear-sky LZRH to higher altitudes, suppressing diabatic ascent in the TTL.
The cloud radiative heating composited here, particularly the in-cloud heating (below $0.01 \mathrm{~g} / \mathrm{m}^{3}$ IWC contour) and cloud-top cooling feature (above $0.01 \mathrm{~g} / \mathrm{m}^{3}$ IWC contour), corroborates the temperature structure retrieved using the synergistic retrieval method (Fig. 8a). It is also consistent with the finding of Rivoire et al. (2020), who noted, based on an analysis of Constellation Observing System for Meteorology, Ionosphere and Climate (COSMIC) data, a cooling tendency above $100 \mathrm{hPa}$ that is partially attributable to radiative effects.

Figure 11 demonstrates that the qualitative structure of cloud radiative heating and cooling effects changes little with radial distance from the cyclone center. This insensitivity, however, hides the distinct radiative effects of different types of cloud. For instance, it is well known that DCC cools the atmospheric column above it by trapping the thermal fluxes within the cloud, while thin cirrus can warm the air locally by absorbing the thermal emission from the surface (e.g., Fig. 5b of Rivoire et al., 2020). The compensating sign of radiative effects is not evident anywhere in Fig. 11c, despite the fact that cloud types have a strong radial dependence (Fig. 4b). Recognizing that the cloud radiative effects are determined by the cloud optical depth, $\mathrm{BT}_{1231}$ can be used to characterize the radiative effects of different types of clouds owing to its sensitivity to cloud optical depth over tropical ocean FOVs.

To construct a composite of cloud radiative heating with respect to $\mathrm{BT}_{1231}$, cloud profiles at CloudSat footprints are paired with the nearest AIRS spectra. The AIRS FOVs evaluated here are limited to those with scanning angles of less than $14^{\circ}$, which has a negligible $(<3 \%)$ effect on the optical depth, and those with CloudSat samples locations fall within their ground footprints $(13.5 \mathrm{~km})$. A composite of all-sky radiative heating rates over every $1 \mathrm{~K}$ bin of $\mathrm{BT}_{1231}$ is shown in Fig. 12, along with differences relative to clear-sky conditions.

Figure 12 shows that different regimes of cloud radiative effects are well differentiated by $\mathrm{BT}_{1231}$. When $\mathrm{BT}_{1231}$ is colder than $230 \mathrm{~K}$ (indicating thick upper tropospheric clouds, as discussed in Sect. 3), net radiative cooling is observed in the TTL. This net cooling is largely caused by longwave cooling above DCC cloud tops (indicated by IWC contours in Fig. 12). Note that this BT condition (colder than $230 \mathrm{~K}$ ) occurs in more than $50 \%$ of overpasses within a $300 \mathrm{~km}$ radius of the cyclone center (Fig. 4d), indicating that the TTL is dominated by radiative cooling within this range. In this cloud regime, the cloud effect lifts the LZRH to higher altitudes, reaching $19.5 \mathrm{~km}$ when $\mathrm{BT}_{1231}$ is around $200 \mathrm{~K}$. When $\mathrm{BT}_{1231}$ is between 240 and $280 \mathrm{~K}$, noticeable heating emerges near the cloud top (compare Fig. 12a and b), attributable to the deeper penetration of solar radiation into the less opaque cloud layer. When $\mathrm{BT}_{1231}$ is greater than $294 \mathrm{~K}$ (the clear-sky climatological mean value), TTL heating is evident. This TTL heating is accompanied by a substantial increase in CI (cirrus) scenes with increasing $\mathrm{BT}_{1231}$ 
(a) LW, All-sky, [K/day]

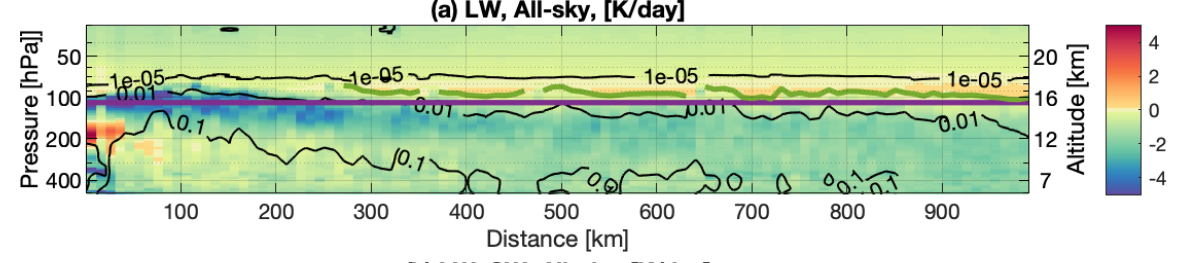

(b) LW+SW, All-sky, [K/day]

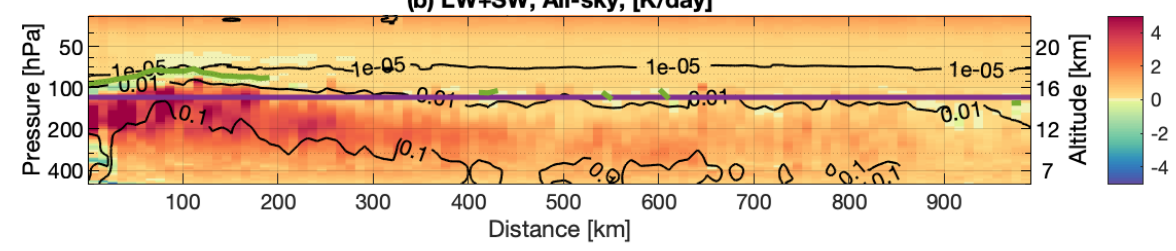

(c) LW, Cloud effects, [K/day] LW, Clear-sky

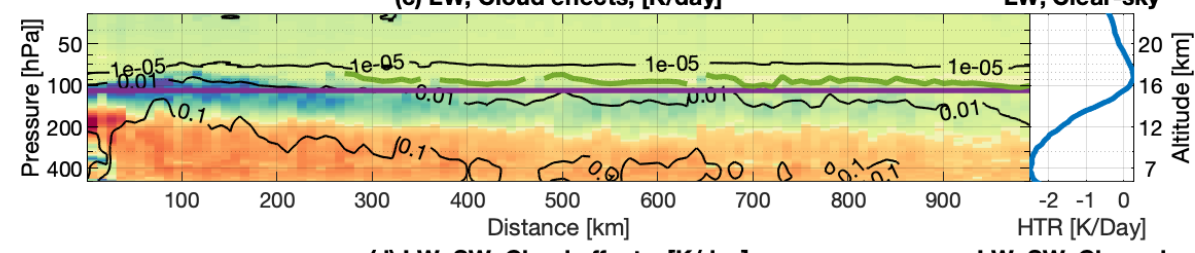

(d) LW+SW, Cloud effects, [K/day] LW+SW, Clear-sky

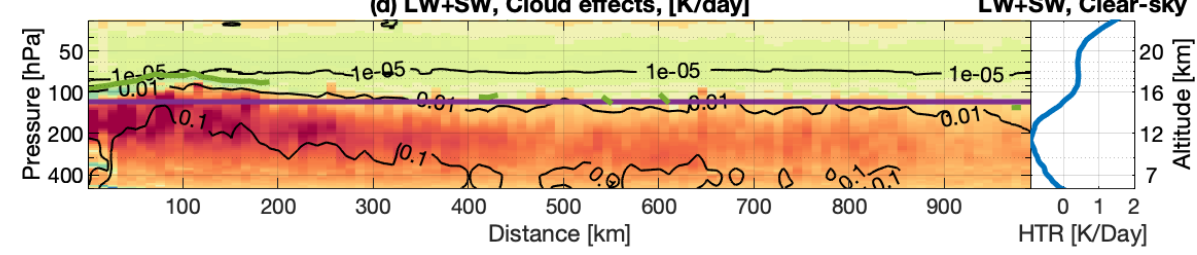

(e) LW+SW, All-sky anomalies, [K/day]

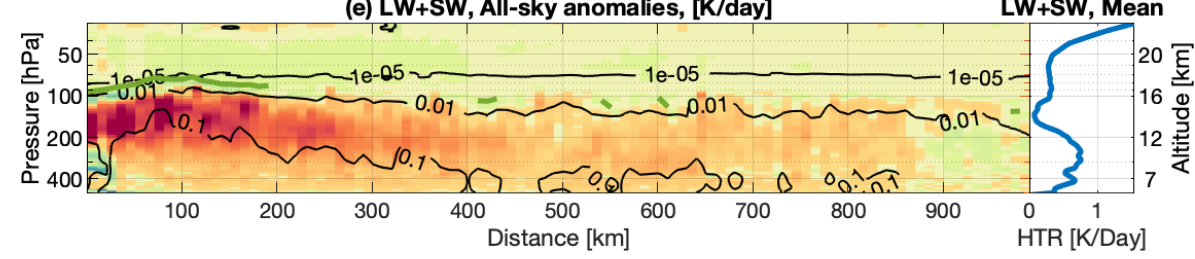

Figure 11. Radiative heating (shading, K/d, from CloudSat 2B-FLXHR-LIDAR) and IWC (black contour, g/m ${ }^{3}$, from DARDAR-Cloud) as a function of distance to the cyclone center. (a) All-sky longwave and (b) net (longwave + shortwave) radiative heating rates. (c, d) The same as (a, b) but for cloud radiative effects, which are defined as the differences between all-sky heating rates and the mean clear-sky heating rate (blue curve in the right panel). (e) The same as (d) but for all-sky net radiative heating anomalies, which are defined as the differences between all-sky heating rates and the mean all-sky heating rate. The magenta line marks the clear-sky LZRH. The green line marks the cloudy-sky LZRH, determined as the vertical position where the heating rate changes from positive to negative.

as shown in Fig. 12f, which suggests the contribution of thin cirrus in the TTL heating as mentioned above.

Furthermore, we compute the net heating anomaly with respect to the all-sky climatology. The all-sky net heating anomaly is then shown as a function of the $\mathrm{BT}_{1231}$ anomaly, which is also defined with respect to the all-sky average, in Fig. 12e. It is clear that cloud effects on TTL heating rates above $16 \mathrm{~km}$ are well differentiated by $\mathrm{BT}_{1231}$ : cooling when the $\mathrm{BT}_{1231}$ anomaly is negative and heating when the $\mathrm{BT}_{1231}$ anomaly is positive. Given that a negative $\mathrm{BT}_{1231}$ anomaly prevails within $1000 \mathrm{~km}$ of the cyclone center (see the black line in Fig. 4d), it is no wonder that Fig. 11 generally shows TTL cooling above tropical cyclones.

The prevalence of TTL radiative cooling in Fig. 12c and d suggests that the diabatic ascent that normally (climatologi- cally) occurs within the TTL is greatly suppressed by cloud radiative effects in a $2000 \mathrm{~km} \times 2000 \mathrm{~km}$ domain surrounding tropical cyclone centers. A hydrated air parcel above a cyclone has to be advected further away from the cyclone centers to experience radiative heating and ascend to the stratosphere.

Finally, it is worth noting a few caveats regarding the cloud radiative effect assessed here. As the cloud radiative effect is measured by the difference in radiative heating between all-sky and clear-sky conditions, the result is subject to differences in surface emissions and thermodynamic conditions between the clear-sky and all-sky situations. We cannot quantify how much of the TTL cooling (as shown in Fig. 12d, e) is directly attributable to clouds because large anomalies in temperature and water vapor (as shown in Fig. 8) also exist 
(a) LW, All-sky, [K/day]

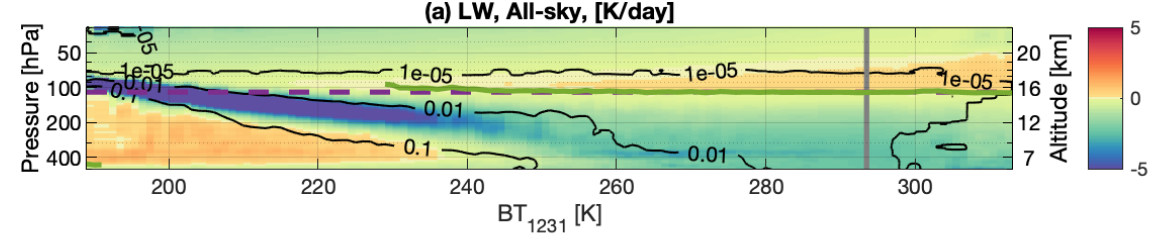

(b) LW+SW, All-sky, [K/day]

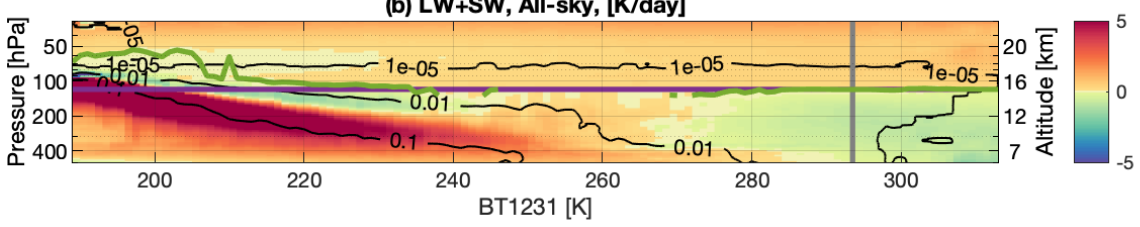

(c) LW, Cloud effects, [K/day]

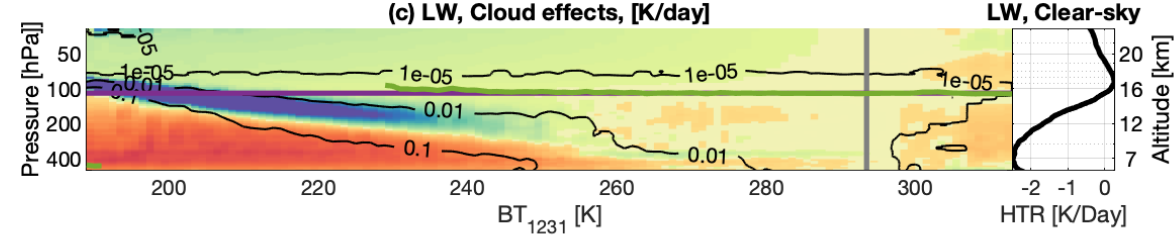

(d) LW+SW, Cloud effects, [K/day]

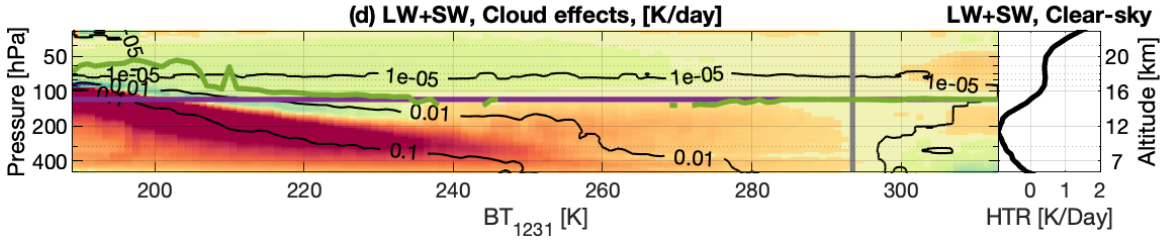

(e) LW+SW, All-sky anomalies, [K/day]
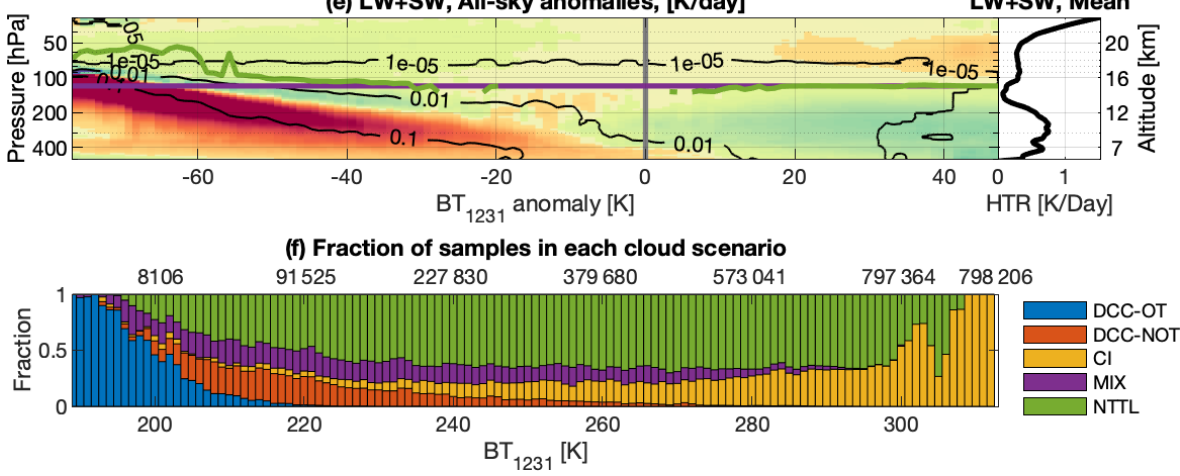

Figure 12. Radiative heating rates (shading, K/d, from CloudSat 2B-FLXHR-LIDAR) and IWC (black contour, g/m³ ${ }^{3}$, from DARDAR-Cloud) as a function of window band radiance $\mathrm{BT}_{1231}(\mathrm{~K}$, from collocated AIRS L1B). (a) All-sky longwave and (b) net (longwave + shortwave) radiative heating rates. $(\mathbf{c}, \mathbf{d})$ The same as $(\mathbf{a}, \mathbf{b})$ but for cloud radiative effects, which are defined as the differences between all-sky heating rates and the mean clear-sky heating rate (black curve in the right panel). (e) The same as (d) but for all-sky net radiative heating anomalies, which are defined as the differences between all-sky and the mean all-sky cyclone overpass (black curve in the right panel). (f) The proportion of samples in each cloud category (classified in Sect. 3.1) of all cloudy overpass samples. The numbers at the top indicate the number of cloudy samples with $\mathrm{BT}_{1231}$ colder than the corresponding temperature marked at the bottom. The magenta line marks the clear-sky LZRH. The green line marks the cloudy-sky LZRH, determined as the vertical position where the heating rate changes from positive to negative.

above tropical cyclones. It is unclear how much these noncloud variables account for the radiative heating anomalies shown in Figs. 11 and 12. Moreover, the CloudSat radiative heating data used here may be subject to errors because their calculation is based on the ECMWF forecast which does not fully capture the above-cyclone temperature and water vapor perturbations (see Fig. 8). It is therefore useful to examine the heating rate change above these tropical cyclones using collocated observations of cloud, temperature, and water vapor profiles from our synergistic retrieval.

\subsection{Heating rate decomposition}

Large temperature and water vapor anomalies in the TTL above tropical cyclones (as depicted in Fig. 8) are detected using the joint AIRS-DARDAR retrieval method. Here, using the radiative transfer model RRTM (Iacono et al., 2000), 
the radiative effects of the cloud, temperature, and water vapor anomalies are isolated as shown in Fig. 13. The shortwave effects of temperature and water vapor are not shown because they are negligible compared to the longwave effects.

Following the partial radiative perturbation (PRP) approach (Wetherald and Manabe, 1988), we measure the radiative effect of a variable by differencing the RRTM computations with perturbed and unperturbed values of this variable. For instance, the radiative effect of cyclonic clouds is measured as

$$
\operatorname{dHTR}(c)=\operatorname{HTR}\left(c, t_{0}, q_{0}\right)-\operatorname{HTR}\left(c_{0}, t_{0}, q_{0}\right) .
$$

Here, HTR denotes the instantaneous heating rate profile and is computed using RRTM and $c, t$, and $q$ denote cloud, temperature, and water vapor profiles from the cyclone samples, respectively. Note that for the $t$ and $q$ profiles, only the portions above $16 \mathrm{~km}$ are of concern and replaced in the PRP computation. Variables with subscript 0 denote values from the all-sky climatology. The mean instantaneous longwave and net radiative heating rate profiles for DCC-OT, TTLOTHER, and NTTL clouds are shown in Fig. 13. The radiative effects of temperature and water vapor are examined in both all-sky conditions, denoted by the subscript cld in Fig. $13 \mathrm{~g}$ and $\mathrm{h}$, and clear-sky conditions $(c=0)$, denoted by the subscript clr in Fig. 13c and d.

By comparing Fig. 13a and e, we find that the total net radiative effect, $\operatorname{dHTR}_{\text {net }}(c, t, q)$, is dominated by clouds. The sign and magnitude of the cloud radiative effect are consistent with our previous conclusion, namely a cooling effect at the cloud top as indicated by a cold $\mathrm{BT}_{1231}$ anomaly (Fig. 12a, e). The cloud longwave cooling effect around $90 \mathrm{hPa}$ is much larger above DCC-OT clouds due to higher cloud ice water content near this level.

As seen in Fig. 13g and h, above $80 \mathrm{hPa}$ where cloud ice diminishes, the all-sky radiative effects of anomalies in temperature and humidity become more important. Temperature modulates longwave emission in ways that damp the temperature anomalies (compare Fig. 13g to 9c). For water vapor, a moistening at the cold point increases thermal emissivity, which leads to cooling at the cold point and heating at lower levels. Therefore, TTL hydration above DCC-OT and NTTL clouds leads to radiative cooling in the TTL. Assuming a similar pattern in thermodynamic anomalies to what is shown in Fig. 9c and $\mathrm{d}$ in the clear sky, we compute the radiative effects of temperature and water vapor above $80 \mathrm{hPa}$ in the clear sky (Fig. 13c, d) and find that they are similar to the all-sky results.

Despite the limited vertical resolution of the water vapor retrieval, as discussed in Appendix A, it is unambiguous that TTL hydration leads to radiative cooling. This suggests that moisture above overshooting convection radiatively cools the layer, thus constraining the moist air from diabatically ascending to higher altitudes. This finding is consistent with the robust radiative cooling seen above cyclones in Fig. 12.

\section{Conclusions}

In this study, we aim to understand the impacts of tropical cyclones on thermodynamic conditions in the TTL using multiple instruments aboard the A-Train satellites. We use a tropical cyclone (TC) overpass product to composite multiple observation products relative to 947 tropical cyclone center locations over the northern part of the West Pacific region to ascertain the effect of cyclones. To address the lack of reliable observations of temperature and water vapor when thick convective clouds are present, a retrieval scheme proposed by Feng and Huang (2018) is improved by incorporating cloud properties measured by active sensors to retrieve the abovecyclone temperature and water vapor profiles simultaneously.

This study finds that tropical cyclones substantially increase TTL clouds. These TTL clouds occur frequently above tropical cyclones, mostly as non-convective high clouds above a clear troposphere (CI category, Fig. 4b). This distribution of high clouds is consistent with in situ aircraft observations (e.g., Jensen et al., 2013). Our finding emphasizes that the occurrence of TTL cloud is 0.372 on average (Figs. 3a and 4a) within the $2000 \mathrm{~km} \times 2000 \mathrm{~km}$ cyclonecentered composite domain, highlighting the importance of tropical cyclones in generating TTL clouds. In contrast to the horizontally extensive occurrence of TTL cloud cover, TTL cloud ice is most concentrated near the cyclone center (Figs. 3c and 4a), as a result of direct convective overshooting and detrainment (Fig. 4c). Furthermore, we find that the northwestern quadrant of the composite domain is less impacted by cyclones (Fig. 3b, j). There is also a persistent southwest preference in TTL cloud ice and DCCs.

Both MLS v4.2 and the joint AIRS-DARDAR method are used to evaluate the impact of tropical cyclones on temperature and water vapor by compositing these fields as a function of radial distances to cyclone centers (Fig. 7). Differences between the products are noticeable in this study, and they can arise for several reasons. First, contamination of cloud may cause artifacts in the MLS v4.2 product, especially in temperature, that may not be effectively screened out by the cloud flag of the product (Schwartz et al., 2008; Livesey et al., 2017). Second, sampling differences (MLS is off-nadir while AIRS, CPR, and CALIOP are nadir-looking) caused by instrument viewing geometry and the selection of samples can be substantial (see Fig. 5). Due to issues caused by cloud contamination, any MLS FOVs containing high cloud are excluded in this study for both temperature and water vapor. The implication of the joint AIRS-DARDAR method, however, exclusively selects FOVs that contain thick high clouds to perform the retrieval. Hence, the thermodynamic conditions of samples with or without high clouds can lead to large differences in the constructed cyclone composites. Third, the horizontal resolution of the joint AIRS-DARDAR method is at least 10 times finer than that of MLS. As a result, the joint AIRS-DARDAR method better captures the horizontal distribution pattern (Feng et al., 2021). Last, compared to MLS, 

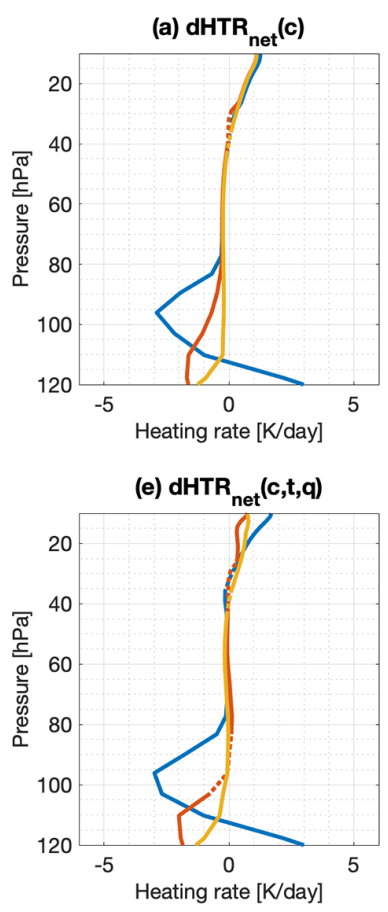
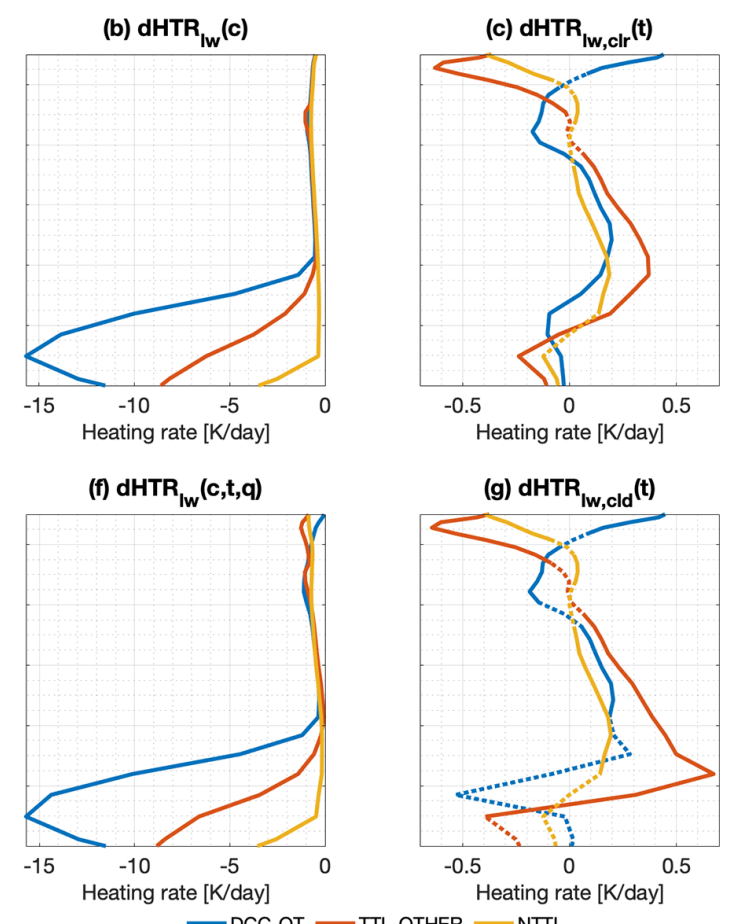
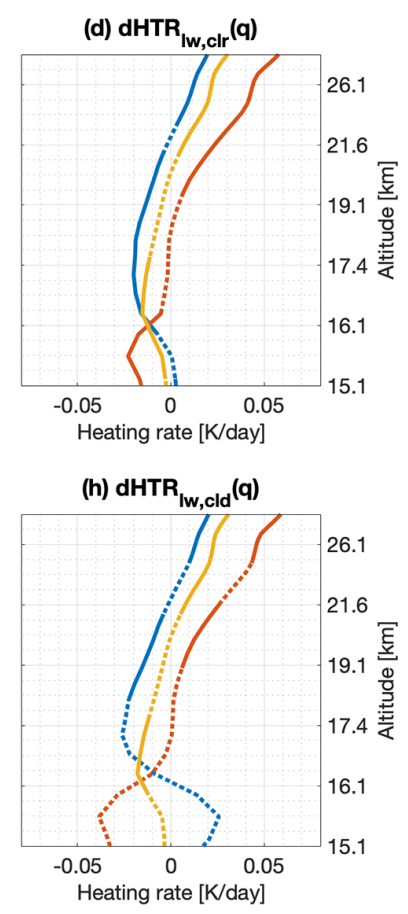

Figure 13. The radiative heating effects of cloud, temperature, and water vapor. (a) The net effects of cloud, $\mathrm{dHTR}_{\text {net }}(c)$. (b) The longwave effects of cloud, $\mathrm{dHTR}_{\mathrm{lw}}(c)$. (c) The longwave effects of temperature for clear-sky conditions, $\mathrm{dHTR}_{\mathrm{lw}, \mathrm{clr}}(t)$. (d) The longwave effects of water vapor for clear-sky conditions, $\operatorname{dHTR}_{1 \mathrm{w}, \mathrm{clr}}(q)$. (e) The net effects of cloud, temperature, and water vapor, collectively, $\mathrm{dHTR}_{\text {net }}(c, t, q)$. (f) The longwave effects of cloud, temperature, and water vapor, collectively, $\operatorname{dHTR}_{\mathrm{lw}}(c, t, q)$. (g) The longwave effects of temperature for cloudy-sky conditions, $\operatorname{dHTR}_{1 \mathrm{w}, \mathrm{cld}}(t)$. (h) The longwave effects of water vapor for cloudy-sky conditions, $\operatorname{dHTR}_{1 \mathrm{w}, \mathrm{cld}}(q)$.

the joint AIRS-DARDAR method has higher precision and a higher vertical resolution for temperature but lower precision and a lower vertical resolution for water vapor.

Hence, the joint AIRS-DARDAR method is more advantageous in evaluating temperature fields related to tropical cyclone events. Figure 8 shows a noticeable pattern of vertically oscillating temperature anomalies above tropical cyclones that lifts the cold-point tropopause level to higher altitudes. After investigating the cloud radiative effects in Sect. 4, we find that the signs of the temperature anomaly agree well with cloud effects on radiative heating rates, for example, the in-cloud warming (below the $0.01 \mathrm{~g} / \mathrm{m}^{3}$ IWC contour in Figs. 8a and 12d) due to shortwave heating and cloud-top cooling due to longwave cooling. Environmental cooling above clouds may also facilitate the formation of TTL clouds that deplete moisture from the detrainment of tropical cyclones, as indicated by the drier TTL over nonovershooting clouds. The cooling effect of tropical cyclones on cold-point temperatures also implies the importance of deep convection in modulating the stratospheric water vapor, so a strong linkage between stratospheric water vapor and cold-point temperature, as noted by Randel and Park (2019), cannot preclude the role of convection in water vapor variability.
The joint AIRS-DARDAR method is also used to investigate overall (de)hydration above overshooting deep convective clouds and other non-overshooting clouds. Figure $8 \mathrm{~b}$ suggests that cyclones mostly hydrate the atmospheric column above them. Above overshooting deep convective clouds, the LIWV is found to be $40 \%$ higher than the local climatology (Fig. 10b). Substantial hydration is also found above clouds located beneath $16 \mathrm{~km}$ (NTTL). We suspect that this is likely from advected moist plumes from overshooting injection, though we are unable to prove these suspicions at this time. After isolating different cloud categories, dehydration is found above only non-overshooting TTL clouds (TTLOTHER) which are coincidently associated with colder temperatures than those of other cloud categories (Figs. 9 and 10 ). The coexistence of dehydration (as opposed to the moistening above other cloud categories), cold anomalies, and non-overshooting TTL clouds suggests that in this situation water vapor is likely deposited onto ice particles.

By comparing the nearest thermodynamic profiles from the ERA5 reanalysis (Fig. 8c, f) to the synergistic retrieval (Fig. 8a, d), we find that the cold anomaly in ERA5 is at a lower altitude, which is partially attributable to biases in cloud ice in the reanalysis. The moistening signals around $80 \mathrm{hPa}$, as detected by the synergistic retrieval and MLS (Fig. 8d, e), are not shown in ERA5. These results sug- 
gest that the above-cyclone water vapor in reanalysis products may be susceptible to the ability of models to simulate cloud ice and temperature using convective parameterizations (Wright et al., 2020).

Furthermore, we find that the cloud radiative effect is well differentiated by $\mathrm{BT}_{1231}$. Clouds heat the TTL via radiation when $\mathrm{BT}_{1231}$ shows a warm anomaly and cool the TTL when $\mathrm{BT}_{1231}$ shows a cold anomaly. Radiative cooling prevails above DCCs and thick anvils, which greatly reduce $\mathrm{BT}_{1231}$. Radiative warming becomes more noticeable away from the cyclone center over thin cirrus. The radiative cooling anomaly further impacts the diabatic heating budget above tropical cyclones, suppressing diabatic ascent and air mass transport across isentropic surfaces to higher altitudes. It remains unclear how this suppressed diabatic ascent, together with the strong horizontal divergence created by the pressure gradient above the cyclone, affects stratospheretropopause exchange and the water vapor budget. To elucidate this effect in the trajectory modeling in future work will require the use of instantaneous radiative heating computed from deep convection-perturbed TTL thermodynamic conditions (temperature, humidity, and cloud), as opposed to climatologic or reanalysis heating profiles that do not properly represent the convective perturbations.

Finally, we would like to highlight the advantages of the synergistic method in retrieving the above-cloud thermodynamic conditions. This method takes advantage of collocated infrared hyperspectra and active sensors and is capable of retrieving temperature and water vapor for overcast cloud conditions. These features are highly complementary to other datasets, including MLS v4.2 and AIRS L2 v6, that are limited to clear-sky conditions. So far, this approach has been applied to only limited samples in the vicinity of tropical cyclones. It can be applied to other tropical and extratropical convective events, with potential implementation in other hyperspectral infrared sounders, such as IASI (Infrared Atmospheric Sounding Interferometer), CrIS (Cross-track Infrared Sounder), IRS (Infrared Sounder), and GIIRS (Geostationary Interferometric Infrared Sounder), to provide thermodynamic information over deep convective clouds on a global scale in future research.

\section{Appendix A: Joint AIRS-DARDAR retrieval algorithm}

Feng and Huang (2018) applied a cloud-assisted retrieval to AIRS L1B infrared radiance from FOVs filled with deep convective clouds, assuming a blackbody cloud top. This method retrieves atmospheric temperature and humidity profiles above the cloud top as described in Sect. 2.1 and is especially advantageous for overcast conditions during tropical cyclone events. An updated version of this retrieval method has been validated by Feng et al. (2021) using simulation experiments and is adopted here. We briefly describe this re- trieval method below and interested readers can find more details of this retrieval method from Feng et al. (2021).

In this method, we retrieve atmospheric states $\boldsymbol{x}$ that include temperature, humidity, ice water content (IWC), and effective radius as an optimal estimation (Rodgers, 2000) that combines the a priori of $\boldsymbol{x}$ and the observation vector, $\boldsymbol{y}$. The relationship between the state vector and the observation vector is expressed as

$$
\begin{aligned}
\boldsymbol{y} & =F\left(x_{0}\right)+\frac{\partial F}{\partial \boldsymbol{x}}\left(\boldsymbol{x}-\boldsymbol{x}_{0}\right)+\boldsymbol{\varepsilon} \\
& =\boldsymbol{y}_{0}+\mathbf{K}\left(\boldsymbol{x}-\boldsymbol{x}_{0}\right)+\boldsymbol{\varepsilon},
\end{aligned}
$$

where $F$ is the forward model; $\mathbf{K}$ is the Jacobian matrix, which is a first-order linear approximation of $F$; and $\varepsilon$ is the residual. $\boldsymbol{x}_{0}$ is the first guess, for which we use the mean of the a priori. Following the synergistic retrieval method (Feng et al., 2021), additional observation vectors are added, so that $\boldsymbol{y}$ is formed as $\left[\boldsymbol{y}_{\mathrm{rad}}, \boldsymbol{y}_{\mathrm{iwc}}, \boldsymbol{y}_{\mathrm{R}_{\mathrm{e}}}, \boldsymbol{y}_{\mathrm{atm}}\right] . \boldsymbol{y}_{\mathrm{rad}}$ is the infrared hyperspectra from the AIRS L1B product, for which 1109 channels are selected based on the radiometric quality of each channel. This rigorous channel selection also excludes O3 absorption channels $\left(980-1140 \mathrm{~cm}^{-1}\right), \mathrm{CH}_{4}$ absorption channels $\left(1255-1355 \mathrm{~cm}^{-1}\right)$, and shortwave infrared channels $\left(2400-2800 \mathrm{~cm}^{-1}\right) \cdot \boldsymbol{y}_{\text {iwc }}$ is a $2 \mathrm{~km}$ vertical IWC profile from the DARDAR-Cloud product, from $1.5 \mathrm{~km}$ below the DARDAR-identified cloud top to $0.5 \mathrm{~km}$ above it. $\boldsymbol{y}_{\mathrm{R}_{\mathrm{e}}}$ is the effective radius, which holds constant through the vertical layers of an atmospheric column. $\boldsymbol{y}_{\mathrm{atm}}$ is the temperature and humidity profile from the nearest ERA5 reanalysis product (hourly, $0.25 \times 0.25$ ). The a priori dataset is obtained from the AIRS L2 supplementary product for temperature and water vapor and from the DARDAR-Cloud product for IWC and effective radius using data from 2006 to 2014 in the northern part of the West Pacific.

The forward model to convert the atmospheric states to $\boldsymbol{y}_{\text {rad }}$ is a radiative transfer model, the line-by-line version of MODerate resolution atmospheric TRANsmission (MODTRAN 6.0; Berk et al., 2014). Following Feng et al. (2021), user-defined extinction coefficients, single-scattering albedo, and asymmetry factors are input into MODTRAN, assuming vertically uniform optical properties (per unit ice mass) and a solid-column crystal habit. Forward model uncertainties caused by this assumption are evaluated in Feng et al. (2021) and are around $0.1 \mathrm{~K}$ in the mid-infrared. To relate $\boldsymbol{x}$ to $\boldsymbol{y}_{\mathrm{iwc}}$ and $\boldsymbol{y}_{\mathrm{atm}}$, the forward model and the corresponding Jacobian matrix work as a linear interpolation matrix (Bowman et al., 2006; Feng et al., 2021).

Using the Gaussian-Newton method, the best estimate of $\boldsymbol{x}, \hat{\boldsymbol{x}}$, is iteratively solved as

$$
\begin{aligned}
\hat{\boldsymbol{x}}_{i+1} & =\boldsymbol{x}_{0}+\left(\mathbf{K}_{i}^{\mathrm{T}} \mathbf{S}_{\boldsymbol{\varepsilon}}^{-1} \mathbf{K}_{i}+\mathbf{S}_{\mathrm{a}}^{-1}\right)^{-1} \mathbf{K}_{i}^{\mathrm{T}} \mathbf{S}_{\boldsymbol{\varepsilon}}^{-1} \\
& \times\left[\boldsymbol{y}-F\left(\hat{\boldsymbol{x}}_{i}\right)+\mathbf{K}_{i}\left(\hat{\boldsymbol{x}}_{i}-\boldsymbol{x}_{0}\right)\right], \\
\hat{\boldsymbol{x}}_{i+1} & =\boldsymbol{x}_{0}+\left(\mathbf{K}_{i}^{\mathrm{T}} \mathbf{S}_{\boldsymbol{\varepsilon}}^{-1} \mathbf{K}_{i}+\mathbf{S}_{\mathrm{a}}^{-1}\right)^{-1} \mathbf{K}_{i}^{\mathrm{T}} \mathbf{S}_{\boldsymbol{\varepsilon}}^{-1} \\
& \times\left[\boldsymbol{y}-F\left(\hat{\boldsymbol{x}}_{i}\right)\right]+\mathbf{A}\left(\hat{\boldsymbol{x}}_{i}-\boldsymbol{x}_{0}\right),
\end{aligned}
$$


where the subscript $i$ refers to the $i$ th time step. $\mathbf{S}_{\mathrm{a}}$ and $\mathbf{S}_{\boldsymbol{\varepsilon}}$ are the covariance matrix of the a priori dataset and the observation vector, respectively, which are constructed in the same way as in Feng et al. (2021). More specifically, $\mathbf{S}_{\boldsymbol{\varepsilon}}$ is a diagonal matrix. The diagonal elements of $\mathbf{S}_{\boldsymbol{\varepsilon}}$ for $\boldsymbol{y}_{\text {rad }}$ contain the sum of the square of radiometric noise of the instrument and the forward model uncertainty. For $\boldsymbol{y}_{\text {iwc }}$, they contain the square of a doubling of posterior uncertainty in the IWC profile which is provided by the DARDAR-Cloud product at every measurement location and vertical level. For $\boldsymbol{y}_{\mathrm{R}_{\mathrm{e}}}$, they contain the square of a doubling of posterior uncertainty in the effective radius of a vertical layer where optical depth measured from the cloud top reaches unity (Feng et al., 2021). The $\mathbf{S}_{\boldsymbol{\varepsilon}}$ for $\boldsymbol{y}_{\mathrm{atm}}$ is denoted as $\mathbf{S}_{\mathrm{atm}}$; it contains the square of a doubling of the root-mean-square difference between collocated ERA5 and MLS v4.2 products at every vertical level of ERA5. These uncertainty estimations are amplified in order to account for uncertainties caused by differences in the size and location of FOVs of different instruments.

The $\mathbf{A}$ in Eq. (A3) is referred to as the averaging kernel. Given a "truth" state vector that $F\left(\boldsymbol{x}_{\mathrm{t}}\right)=\boldsymbol{y}$, it links the truth state to the retrieved state so that

$\hat{\boldsymbol{x}}-\boldsymbol{x}_{0}=\mathbf{A}\left(\boldsymbol{x}_{\mathrm{t}}-\boldsymbol{x}_{0}\right)$.

Therefore, it regulates the vertical shape of the posterior estimation.

The iteration converges when

$\left(\hat{\boldsymbol{x}}_{i+1}-\hat{\boldsymbol{x}}_{i}\right)^{\mathrm{T}} \mathbf{S}\left(\hat{\boldsymbol{x}}_{i+1}-\hat{\boldsymbol{x}}_{i}\right) \ll N$,

where $N$ is the dimension of the state vector and $\mathbf{S}$ is the posterior covariance matrix, which is computed combining the covariance matrix of a priori and observation vectors:

$\mathbf{S}=\left(\mathbf{S}_{\mathrm{a}}^{-1}+\mathbf{K}^{\mathrm{T}} \mathbf{S}_{\boldsymbol{\varepsilon}}^{-1} \mathbf{K}\right)^{-1}$.

Therefore, the retrieved state converges to $\hat{\boldsymbol{x}}$ with an uncertainty range equivalent to the square root of the diagonal element of the posterior covariance matrix $\mathbf{S}$.

Feng et al. (2021) used a simulation experiment to evaluate a synergistic retrieval approach that combines infrared spectra $\left(\boldsymbol{y}_{\text {rad }}\right)$ with another observation vector that includes the IWC product from the collocated observation vector, denoted as $\boldsymbol{y}_{\mathrm{iwc}}$, and additional atmospheric observations, denoted as $\boldsymbol{y}_{\text {atm }}$. In this simulation experiment, the truth atmospheric condition is simulated from a cloud-resolving model during a tropical cyclone event. We mimic the infrared spectra from AIRS observation by adding synthetic noise to the forward-model-simulated infrared radiances that follow the spectral response function of AIRS. The IWC observation is simulated by perturbing the truth IWC profile following the mean posterior uncertainty range provided by the DARDARCloud product within $1000 \mathrm{~km}$ of cyclone centers. Therefore, the simulation experiment is designed to evaluate the realistic retrieval performance above thick upper tropospheric clouds using AIRS L1B and DARDAR-Cloud products, with the same $\mathbf{S}_{\boldsymbol{\varepsilon}}$ as for the observation vectors.

The synergistic retrieval performed here is similar to Case 4 in Feng et al. (2021); the only differences are in the a priori dataset and the $\boldsymbol{y}_{\mathrm{atm}}$, which Feng et al. (2021) constructed hypothetically using numerical model simulation. To examine the capacity of the retrieval method in revealing the realistic thermodynamic conditions, a simulation experiment similar to Feng et al. (2021) is performed here, using the a priori dataset and $\mathbf{S}_{\boldsymbol{\varepsilon}}$ we introduced earlier. Figure A1 shows the horizontal distribution of temperature and water vapor at $81 \mathrm{hPa}$, as well as the integrated water vapor above $16 \mathrm{~km}$ from the simulated truth, the prior, the nearest ERA5 $\left(\boldsymbol{y}_{\mathrm{atm}}\right)$, and the posterior of the retrieval. In Fig. A1, the posterior shows a noticeable improvement compared to the prior and $\boldsymbol{y}_{\mathrm{atm}}$ in reducing the mean biases and root-mean-squareerror (RMSE). As a result, the posterior reveals the spatial feature of the truth, namely a moister and colder cyclone center.

According to Eqs. (A5) and (A6), the precision of this synergistic retrieval algorithm is given by the posterior uncertainty $\mathbf{S}$, which is shown in Fig. A2. The posterior uncertainty is within $1 \mathrm{~K}$ in temperature and is around $0.5 \mathrm{ppmv}$ in water vapor at around $80 \mathrm{hPa}$. While the uncertainty in IWC is equivalent to that of the DARDAR-Cloud product, the simulation experiment conducted by Feng et al. (2021) showed that the retrieval is able to reduce the mean biases and RMSE in collocated IWC products caused by issues such as footprint mismatch.

Compared to other current satellite observational products in the UTLS, this retrieval has several advantages: first, the relatively small sampling footprint $(15 \mathrm{~km}$, the same as the size of the AIRS instantaneous FOV in the nadir) compared to limb-viewing sounders $(>100 \mathrm{~km})$ is beneficial for capturing small-scale variability directly impacted by deep convection; second, the ability to retrieve temperature and water vapor above storms simultaneously; third, the ability to retrieve atmospheric profiles near the cloud top. The simulation experiment conducted by Feng et al. (2021) evidenced that the synergistic method is capable of sounding the temperature profile near and slightly below the cloud top (within a cloud optical depth of 1), while other products may not perform all-sky retrieval (AIRS L2; Susskind et al., 2003) or may be degraded by cloud presence (MLS v4.2; Schwartz et al., 2008; Livesey et al., 2017).

As depicted in the simulation experiment, the synergistic retrieval reveals the spatial variation in temperature and humidity. The retrieval is sensitive to the vertical variation in temperature (Fig. A3a, b) but is not as sensitive to the vertical variation in water vapor (Fig. A3c, d). The vertical resolution of water vapor retrieval is coarse because the mid-infrared channels are less sensitive to the dry stratosphere, leading to a strong smearing effect of the averaging kernel (Feng and Huang, 2018). This smearing effect is illustrated in Fig. A3. 
In this test, we increase the temperature at every $20 \mathrm{hPa}$ interval by $5 \mathrm{~K}$ as shown in Fig. A3a; this corresponds to the term $\boldsymbol{x}_{\mathrm{t}}-\boldsymbol{x}_{0}$ in Eq. (A3). Similarly, the water vapor mixing ratio at every $20 \mathrm{hPa}$ interval is increased by $50 \%$ (considering the water vapor radiative effect is logarithmically scaled), as shown in Fig. A3c. The responses from the averaging kernel are then calculated using Eq. (A3), which are shown in Fig. A3b and d for temperature and water vapor, respectively. Figure A3a and b show that the retrieved temperature responds well to perturbation at different vertical ranges. However, Fig. A3c and d show that the fine-scale water vapor perturbation would result in vertically broad, bottomheavy water vapor anomalies in the retrieval. Nevertheless, the retrieval determines the changes in LIWV properly to detect (de)hydration. This is verified by the tests illustrated in Fig. A3c. Here, we prescribe random hydrations or dehydrations in randomly selected $20 \mathrm{hPa}$ thick layers between 20 and $100 \mathrm{hPa}$, following the same pattern as in Fig. A3c, for 1000 cases. We find that the LIWV changes produced by the averaging kernel approach the truth better at higher altitudes, suggesting that the retrieval is more sensitive to perturbations at higher altitudes.
To evaluate the effects of cyclones on water vapor, samples above cyclones are compared to the climatology computed from the multi-year monthly mean of MLS data at the same grid as that of the retrieval samples. To remove the systematic bias caused by the higher vertical resolution of the MLS product, the MLS climatology is converted to the same vertical resolution using the averaging kernel of the synergistic retrieval, following Eq. (A3) The mean of the converted climatology profiles at retrieved sample locations is shown in Fig. 9b with a black line, while the mean of retrieved water vapor anomalies in comparison with this converted climatology is shown in Figs. 8d and 9d. These anomalies measure the impacts of cyclones. We note that this bias correction procedure affects the vertical structure of the anomaly in water vapor but has a negligible impact on the anomaly in LIWV. Therefore, the conclusion on the hydration and dehydration impacts as shown in Fig. 10 is robust.
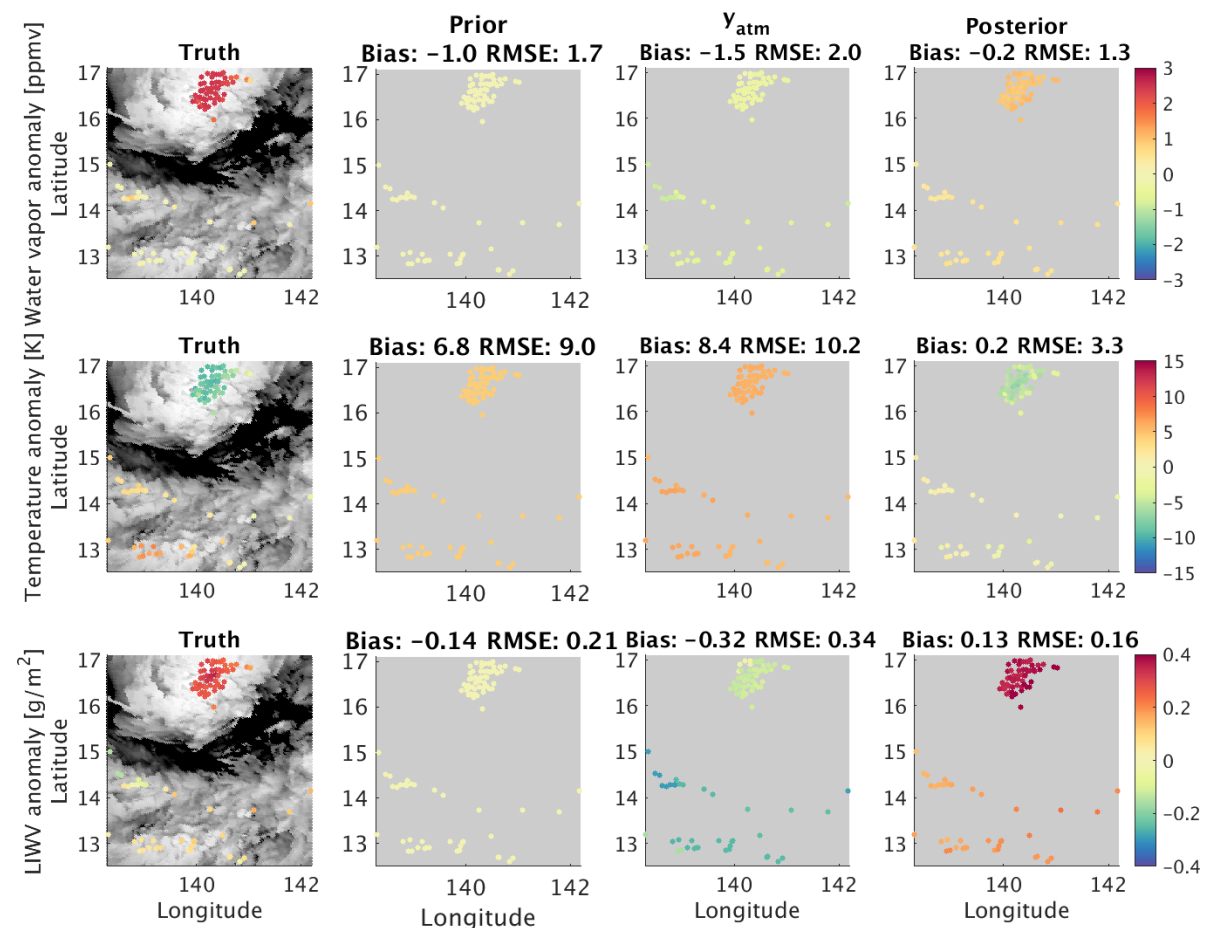

Figure A1. Horizontal distributions of the anomalies, defined as the deviation from the all-sky mean of the simulation field, in water vapor (in units of ppmv, upper panels), temperature (in units of $\mathrm{K}$, middle panels) at $81 \mathrm{hPa}$, and layer integrated water vapor between 110 and $70 \mathrm{hPa}$ (in the units of $\mathrm{g} / \mathrm{m}^{2}$, lower panels). The truth fields are shown in the first column, with the background shaded in grey for BT 1231 . The other columns show the distribution in the prior, nearest ERA5 ( $\left.\boldsymbol{y}_{\mathrm{atm}}\right)$, and the posterior of the retrieval. 

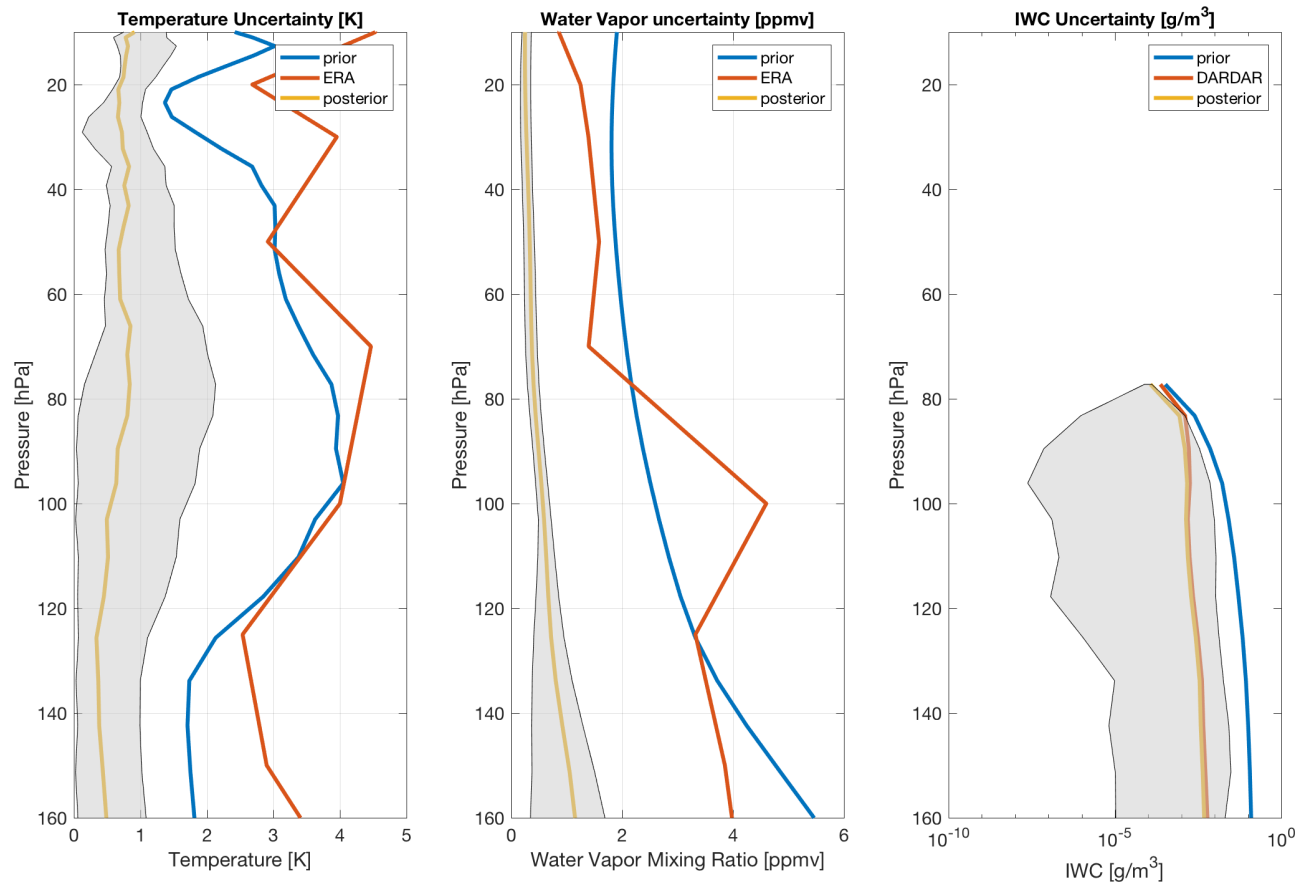

Figure A2. Uncertainties in temperature, water vapor mixing ratio, and IWC, estimated from the average of 2735 retrieved profiles with various cloud-top heights. Blue, orange, and yellow curves show uncertainties in the prior $\left(\mathbf{S}_{\mathrm{a}}\right)$, the ERA5 $\left(\mathbf{S}_{\text {model }}\right)$, and the posterior $\left(\mathbf{S}_{\text {post }}\right)$, respectively. The grey-shaded area is the range of posterior uncertainties.
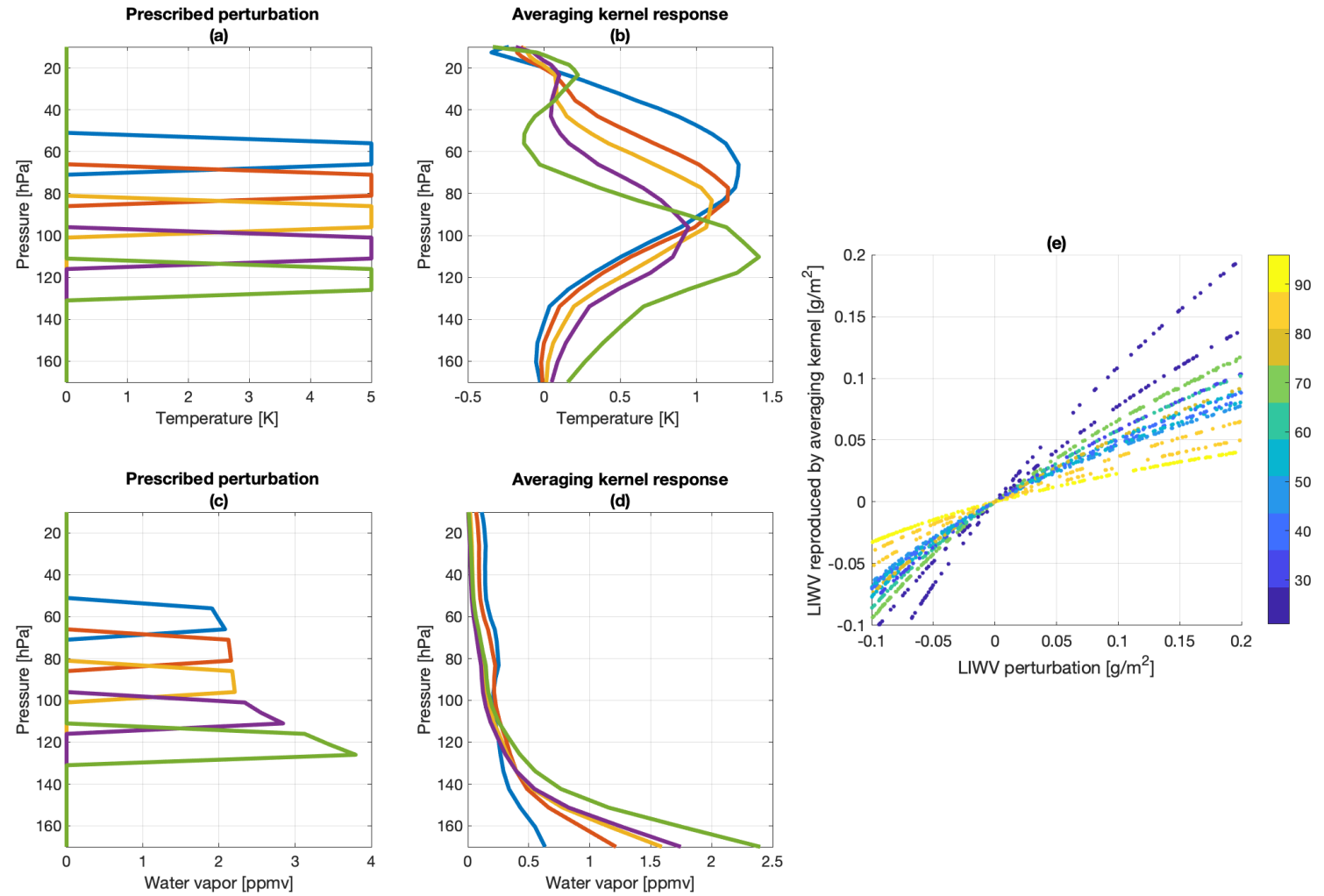

Figure A3. Averaging kernel responses to temperature and water vapor perturbation in thin layers. (a) Prescribed perturbation and (b) the response of averaging kernel in temperature (K). (c) Prescribed perturbation and (d) the response of averaging kernel in water vapor (ppmv). (e) LIWV perturbation $\left(\mathrm{g} / \mathrm{m}^{2}\right)$ between 100 and $20 \mathrm{hPa}$ reproduced by averaging kernel, color-coded for vertical pressure intervals (hPa) where the perturbation is prescribed. 


\section{Appendix B: Binary classification of overshooting deep convective clouds}

Similarly to previous studies (Aumann and Ruzmaikin, 2013), we investigate the BT of the window channel at wavenumber $1231 \mathrm{~cm}^{-1}\left(\mathrm{BT}_{1231}\right)$ and water vapor absorption channel at wavenumber $1419 \mathrm{~cm}^{-1}\left(\mathrm{BT}_{1419}\right)$. In this section, we use collocated AIRS radiance observations and the DARDAR-Cloud product to evaluate the two metrics quantitatively and to identify the best threshold for determining the DCC-OT clouds.

As shown in Fig. B1, the distributions of $\mathrm{BT}_{1231}$ and $\Delta \mathrm{BT}$ of overshooting DCCs resemble the Gaussian distribution in the intervals of $[185,210] \mathrm{K}$ and $[-2,12] \mathrm{K}$, respectively. To find the optimized threshold for DCC-OT classification, we calculate the accuracy and the F score of DCC-OT classification combining $\mathrm{BT}_{1231} \leq \varepsilon_{\mathrm{BT}}$ and $\Delta \mathrm{BT} \leq \varepsilon_{\Delta \mathrm{BT}}$. The accuracy $(\alpha)$ and the $\mathrm{F}$ score $\left(F_{1}\right)$ are defined as

$\alpha=\frac{\mathrm{TP}+\mathrm{TN}}{\mathrm{TP}+\mathrm{FP}+\mathrm{FN}+\mathrm{TN}}$,

$P=\frac{\mathrm{TP}}{\mathrm{TP}+\mathrm{FP}}$,

$R=\frac{\mathrm{TP}}{\mathrm{TP}+\mathrm{FN}}$,

$F_{1}=2 \times \frac{R \times P}{R+P}$,

where TP, TN, FP, and FN are the number of true positives, true negatives, false positives, and false negatives, respectively. While $P$ and $R$ represent the precision and recall (equivalent with true positive rate) of this classification, the F score considers both by a harmonic average of the two factors.
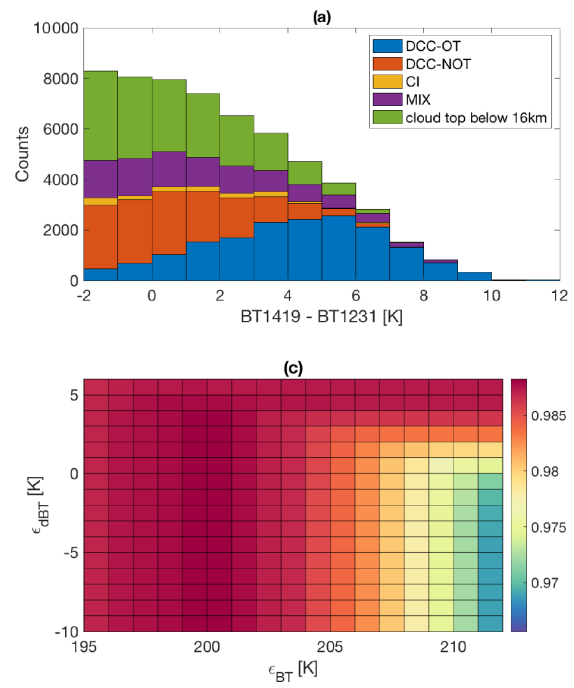

As indicated by Fig. B1c, the accuracy of the classification is around 0.985 when $\varepsilon_{\mathrm{BT}} \leq 204 \mathrm{~K}$ or $\varepsilon_{\triangle \mathrm{BT}} \geq 2 \mathrm{~K}$. However, this high accuracy is partly a result of a small sample size from DCC-OT compared to the total. The F score is therefore used instead. The maximum $F_{1}$ appears when $\varepsilon_{\mathrm{BT}}=203 \mathrm{~K}$ and $\varepsilon_{\triangle \mathrm{BT}}=1 \mathrm{~K}$, although adding the $\varepsilon_{\Delta \mathrm{BT}}$ criterion only increases $F_{1}$ by 0.0004 which is considered to be negligible here. Using $\varepsilon_{\mathrm{BT}}=203 \mathrm{~K}$ leads to an $\mathrm{FP}$ rate at 0.008 and an FN rate at 0.323 . Figure B1b shows that the FP mainly comes from MIX and CI; their cold brightness temperature signal indicates sources from thick anvil cloud near the edge of the DCC system.
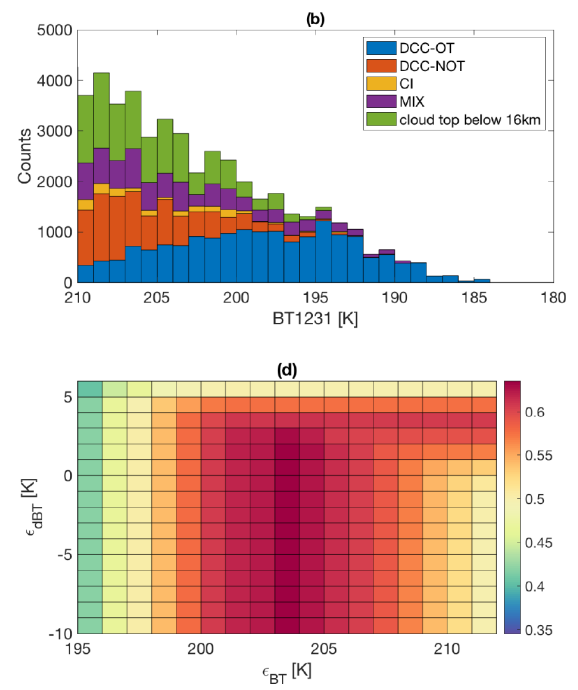

Figure B1. Distribution of (a) $\mathrm{BT}_{1419}-\mathrm{BT}_{1231}$ and (b) $\mathrm{BT}_{1231}$ of AIRS FOVs for four TTL cloud categories and NTTL (cloud top below $16 \mathrm{~km})$. (c) The accuracy (Eq. B1, $\alpha$ ) and (d) F score $\left(F_{1}\right)$ of the DCC-OT classification using the $\mathrm{BT}_{1231} \leq \varepsilon_{\mathrm{BT}}$ and $\mathrm{BT}_{1419}-\mathrm{BT}_{1231} \geq$ $\varepsilon_{\Delta \mathrm{BT}}$ criterion. 
Code availability. Please contact Jing Feng for details of the joint AIRS-DARDAR code.

Data availability. Cloud statistics and thermodynamic conditions retrieved by the joint AIRS-DARDAR method are openly available at https://doi.org/10.17632/fy3gg7ch42.1 (Feng, 2021).

Author contributions. YH conceived the cloud-assisted retrieval idea; JF implemented this idea with improvements using A-Train measurements. JF and YH co-designed the study of the tropical cyclone impacts and collectively wrote this paper.

Competing interests. The authors declare that they have no conflict of interest.

Disclaimer. Publisher's note: Copernicus Publications remains neutral with regard to jurisdictional claims in published maps and institutional affiliations.

Acknowledgements. We thank Jonathon Wright, Xun Wang, Kevin Bloxam, Lei Liu, Louis Rivoire, and the two anonymous reviewers for their constructive comments. This work is supported by grants from the Canadian Space Agency (16SUASURDC and 21SUASATHC) and the Natural Sciences and Engineering Research Council of Canada (RGPIN-2019-04511). Jing Feng acknowledges the support of a Milton Leong Graduate Fellowship of McGill University. We thank Natalie Tourville for making the TC overpass dataset publicly accessible (https://adelaide.cira.colostate. edu/tc/, last access: 28 September 2020). We thank the ICARE Data and Services Center (https://web-backend.icare.univ-lille.fr/ projects/dardar, last access: 13 February 2021) and Julien Delanoë for access to the DARDAR product.

Financial support. This research has been supported by the Canadian Space Agency (grant nos. 16SUASURDC and 21SUASATHC) and the Natural Sciences and Engineering Research Council of Canada (grant no. RGPIN-2019-04511).

Review statement. This paper was edited by Martina Krämer and reviewed by two anonymous referees.

\section{References}

Anderson, J. G., Wilmouth, D. M., Smith, J. B., and Sayres, D. S.: UV dosage levels in summer: Increased risk of ozone loss from convectively injected water vapor, Science, 337, 835-839, 2012. Anthes, R. A., Bernhardt, P. A., Chen, Y., Cucurull, L., Dymond, K. F., Ector, D., Healy, S. B., Ho, S.-P., Hunt, D. C., Kuo, Y.-H., Liu, H., Manning, K., McCormick, C., Meehan, T. K., Randel, W J., Rocken, C., Schreiner, W S., Sokolovskiy, S. V., Syndergaard, S.,
Thompson, D. C., Trenberth, K. E., Wee, T.-K., Yen, N. L., and Zeng, Z.: The COSMIC/FORMOSAT-3 mission: Early results, B. Am. Meteorol. Soc., 89, 313-334, 2008.

Aumann, H. H. and Ruzmaikin, A.: Frequency of deep convective clouds in the tropical zone from 10 years of AIRS data, Atmos. Chem. Phys., 13, 10795-10806, https://doi.org/10.5194/acp-1310795-2013, 2013.

Aumann, H. H., DeSouza-Machado, S. G., and Behrangi, A.: Deep convective clouds at the tropopause, Atmos. Chem. Phys., 11, 1167-1176, https://doi.org/10.5194/acp-11-1167-2011, 2011.

Austin, R. T., Heymsfield, A. J., and Stephens, G. L.: Retrieval of ice cloud microphysical parameters using the CloudSat millimeter-wave radar and temperature, J. Geophys. Res.Atmos., 114, D00A23, https://doi.org/10.1029/2008JD010049, 2009.

Avery, M. A., Davis, S. M., Rosenlof, K. H., Ye, H., and Dessler, A. E.: Large anomalies in lower stratospheric water vapour and ice during the 2015-2016 El Niño, Nat. Geosci., 10, 405-409, 2017.

Berk, A., Conforti, P., Kennett, R., Perkins, T., Hawes, F., and Van Den Bosch, J.: MODTRAN ${ }^{\circledR}$ 6: A major upgrade of the MODTRAN ${ }^{\circledR}$ radiative transfer code, in: 2014 6th Workshop on Hyperspectral Image and Signal Processing: Evolution in Remote Sensing (WHISPERS), 2427 June 2014, Lausanne, Switzerland, IEEE, pp. 1-4, https://doi.org/10.1109/WHISPERS.2014.8077573, 2014.

Bernath, P. F., McElroy, C. T., Abrams, M. C., Boone, C. D., Butler, M., Camy-Peyret, C., Carleer, M., Clerbaux, C., Coheur, P.-F., Colin, R., DeCola, P., DeMazière, M., Drummond, J. R., Dufour, D., Evans, W. F. J., Fast, H., Fussen, D., Gilbert, K., Jennings, D. E., Llewellyn, E. J., Lowe, R. P., Mahieu, E., McConnell, J. C., McHugh, M., McLeod, S. D., Michaud, R., Midwinter, C., Nassar, R., Nichitiu, F., Nowlan, C., Rinsland, C. P., Rochon, Y. J., Rowlands, N., Semeniuk, K., Simon, P., Skelton, R., Sloan, J. J., Soucy, M.-A., Strong, K., Tremblay, P., Turnbull, D., Walker, K. A., Walkty, I., Wardle, D. A., Wehrle, V., Zander, R., and Zou, J.: Atmospheric chemistry experiment (ACE): mission overview, Geophys. Res. Lett., 32, L15S01, https://doi.org/10.1029/2005GL022386, 2005.

Biondi, R., Ho, S.-P., Randel, W., Syndergaard, S., and Neubert, T.: Tropical cyclone cloud-top height and vertical temperature structure detection using GPS radio occultation measurements, J. Geophys. Res.-Atmos., 118, 5247-5259, 2013.

Bowman, K. W., Rodgers, C. D., Kulawik, S. S., Worden, J., Sarkissian, E., Osterman, G., Steck, T., Ming Lou, Eldering, A., Shephard, M., Worden, H., Lampel, M., Clough, S., Brown, P., Rinsland, C., Gunson, M., and Beer, R.: Tropospheric emission spectrometer: Retrieval method and error analysis, IEEE T. Geosci. Remote, 44, 1297-1307, 2006.

Brewer, A.: Evidence for a world circulation provided by the measurements of helium and water vapour distribution in the stratosphere, Q. J. Roy. Meteor. Soc., 75, 351-363, 1949.

Chahine, M. T., Pagano, T. S., Aumann, H. H., Atlas, R., Barnet, C., Blaisdell, J., Chen, L., Divakarla, M., Fetzer, E. J., Goldberg, M., Gautier, C., Granger, S., Hannon, S., Irion, F. W., Kakar, R., Kalnay, E., Lambrigtsen, B. H., Lee, S., Le Marshall, J., Mcmillan, W. W., Mcmillin, L., Olsen, E. T., Revercomb, H., Rosenkranz, P., Smith, W. L., Staelin, D., Strow, L. L., Susskind, J., Tobin, D., Wolf, W., and Zhou, L.: AIRS: Improving weather 
forecasting and providing new data on greenhouse gases, B. Am. Meteorol. Soc., 87, 911-926, https://doi.org/10.1175/BAMS-877-911, 2006.

Corti, T., Luo, B. P., Fu, Q., Vömel, H., and Peter, T.: The impact of cirrus clouds on tropical troposphere-to-stratosphere transport, Atmos. Chem. Phys., 6, 2539-2547, https://doi.org/10.5194/acp6-2539-2006, 2006.

Delanoë, J. and Hogan, R. J.: Combined CloudSatCALIPSO-MODIS retrievals of the properties of ice clouds, J. Geophys. Res.-Atmos., 115, D00H29, https://doi.org/10.1029/2009JD012346, 2010.

Deng, M., Mace, G. G., Wang, Z., and Okamoto, H.: Tropical Composition, Cloud and Climate Coupling Experiment validation for cirrus cloud profiling retrieval using CloudSat radar and CALIPSO lidar, J. Geophys. Res.-Atmos., 115, D00J15, https://doi.org/10.1029/2009JD013104, 2010.

Deng, M., Mace, G. G., Wang, Z., and Lawson, R. P.: Evaluation of several A-Train ice cloud retrieval products with in situ measurements collected during the SPARTICUS campaign, J. Appl. Meteorol. Climatol., 52, 1014-1030, 2013.

Dessler, A., Hintsa, E., Weinstock, E., Anderson, J., and Chan, K.: Mechanisms controlling water vapor in the lower stratosphere: A tale of two stratospheres, J. Geophys. Res.-Atmos., 100, 2316723172, 1995.

Dessler, A., Schoeberl, M., Wang, T., Davis, S., and Rosenlof, K.: Stratospheric water vapor feedback, P. Natl. Acad. Sci. USA, 110, 18087-18091, 2013.

Feng, J.: A-Train observation of thermodynamic conditions above tropical cyclones, Mendeley Data, V1 [data set], https://doi.org/10.17632/fy3gg7ch42.1, 2021.

Feng, J. and Huang, Y.: Cloud-Assisted Retrieval of LowerStratospheric Water Vapor from Nadir-View Satellite Measurements, J. Atmos. Ocean. Tech., 35, 541-553, 2018.

Feng, J., Huang, Y., and Qu, Z.: A simulation-experimentbased assessment of retrievals of above-cloud temperature and water vapor using a hyperspectral infrared sounder, Atmos. Meas. Tech., 14, 5717-5734, https://doi.org/10.5194/amt-145717-2021, 2021.

Fetzer, E. J., Read, W. G., Waliser, D., Kahn, B. H., Tian, B., Vömel, H., Irion, F. W., Su, H., Eldering, A., de la Torre Juarez, M., Jiang, J., and Dang, V.: Comparison of upper tropospheric water vapor observations from the Microwave Limb Sounder and Atmospheric Infrared Sounder, J. Geophys. Res.-Atmos,, 113, D22110, https://doi.org/10.1029/2008JD010000, 2008.

Gettelman, A., Randel, W., Wu, F., and Massie, S.: Transport of water vapor in the tropical tropopause layer, Geophys. Res. Lett., 29, 9-1-9-4, https://doi.org/10.1029/2001GL013818, 2002.

Gettelman, A., Weinstock, E. M., Fetzer, E. J., Irion, F. W., Eldering, A., Richard, E. C., Rosenlof, K. H., Thompson, T. L., Pittman, J. V., Webster, C. R., and Herman, R. L.: Validation of Aqua satellite data in the upper troposphere and lower stratosphere with in situ aircraft instruments, Geophys. Res. Lett., 31, L22107, https://doi.org/10.1029/2004GL020730, 2004.

Henderson, D. S., L'Ecuyer, T., Stephens, G., Partain, P., and Sekiguchi, M.: A multisensor perspective on the radiative impacts of clouds and aerosols, J. Appl. Meteorol. Climatol., 52, 853-871, 2013.

Hersbach, H., Bell, B., Berrisford, P., Hirahara, S., Horányi, A., Muñoz-Sabater, J., Nicolas, J., Peubey, C., Radu, R., Schepers,
D., Simmons, A., Soci, C., Abdalla, S., Abellan, X., Balsamo, G., Bechtold, P., Biavati, G., Bidlot, J., Bonavita, M., De Chiara, G., Dahlgren, P., Dee, D., Diamantakis, M., Dragani, R., Flemming, J., Forbes, R., Fuentes, M., Geer, A., Haimberger, L., Healy, S., Hogan, Robin J., Hólm, E., Janisková, M., Keeley, S., Laloyaux, P., Lopez, P., Lupu, C., Radnoti, G., de Rosnay, P., Rozum, I., Vamborg, Fr., Villaume, S., and Thépaut, J.: The ERA5 global reanalysis, Q. J. Roy. Meteor. Soc., 146, 1999-2049, 2020.

Holloway, C. E. and Neelin, J. D.: The convective cold top and quasi equilibrium, J. Atmos. Sci., 64, 1467-1487, 2007.

Holton, J. R. and Gettelman, A.: Horizontal transport and the dehydration of the stratosphere, Geophys. Res. Lett., 28, 2799-2802, 2001.

Holton, J. R., Haynes, P. H., McIntyre, M. E., Douglass, A. R., Rood, R. B., and Pfister, L.: Stratosphere-troposphere exchange, Rev. Geophys., 33, 403-439, 1995.

Huang, Y., Ramaswamy, V., Huang, X., Fu, Q., and Bardeen, C.: A strict test in climate modeling with spectrally resolved radiances: GCM simulation versus AIRS observations, Geophys. Res. Lett., 34, L24707, https://doi.org/10.1029/2007GL031409, 2007.

Huang, Y., Zhang, M., Xia, Y., Hu, Y., and Son, S.-W.: Is there a stratospheric radiative feedback in global warming simulations?, Clim. Dynam., 46, 177-186, 2016.

Iacono, M. J., Mlawer, E. J., Clough, S. A., and Morcrette, J.-J.: Impact of an improved longwave radiation model, RRTM, on the energy budget and thermodynamic properties of the NCAR community climate model, CCM3, J. Geophys. Res.-Atmos., 105, 14873-14890, 2000.

Jensen, E. J., Pfister, L., Jordan, D. E., Fahey, D. W., Newman, P. A., Thornberry, T., Rollins, A., Diskin, G., Bui, T. P., McGill, M., Hlavka D., Lawson, P. R., Gao, R., Pilewskie, P., Elkins, J., Hintsa, E., Moore, F., Mahoney, M. J., Atlas, E., Stutz, J., Pfeilsticker, K., Wofsy, S. C., Evan, S., and Rosenlof, K. H.: The NASA Airborne Tropical TRopopause EXperiment (ATTREX), SPARC Newsletter, 41, 15-24, 2013.

Jiang, J. H., Su, H., Zhai, C., Perun, V. S., Del Genio, A., Nazarenko, L. S., Donner, L. J., Horowitz, L., Seman, C., Cole, J., Gettelman, A., Ringer, M. A., Rotstayn, L., Jeffrey, S., Wu, T., Brient, F., Dufresne, JL., Kawai, H., Koshiro, T., Watanabe, M., Lécuyer, T. S., Volodin, E. M., Iversen, T., Drange, H., Mesquita, M. D. S., Read, W. G., Waters, J. W., Tian, B., Teixeira, J., and Stephens, G. L.: Evaluation of cloud and water vapor simulations in CMIP5 climate models using NASA "A-Train" satellite observations, J. Geophys. Res.-Atmos., 117, D14105, https://doi.org/10.1029/2011JD017237, 2012.

Jiang, J. H., Su, H., Zhai, C., Wu, L., Minschwaner, K., Molod, A. M., and Tompkins, A. M.: An assessment of upper troposphere and lower stratosphere water vapor in MERRA, MERRA2, and ECMWF reanalyses using Aura MLS observations, J. Geophys. Res.-Atmos., 120, 11468-11485, https://doi.org/10.1002/2015JD023752, 2015.

L'Ecuyer, T. S. and Jiang, J. H.: Touring the atmosphere aboard the A-Train, in: AIP Conference Proceedings, American Institute of Physics, 1401, 245-256, https://doi.org/10.1063/1.3653856, 2011.

Lee, K.-O., Dauhut, T., Chaboureau, J.-P., Khaykin, S., Krämer, M., and Rolf, C.: Convective hydration in the tropical tropopause layer during the StratoClim aircraft campaign: pathway of an ob- 
served hydration patch, Atmos. Chem. Phys., 19, 11803-11820, https://doi.org/10.5194/acp-19-11803-2019, 2019.

Livesey, N., Read, W., Wagner, P., Froidevaux, L., Lambert, A., Manney, G., Millán Valle, L., Pumphrey, H., Santee, M., Schwartz, M., Wang, S., Fuller, R., Jarnot, R., and Knosp, B. : Version $4.2 \times$ Level 2 data quality and description document, JPL D-33509 Rev. C, available at: https://mls.jpl.nasa.gov/data/ v4-2_data_quality_document.pdf (last access: 11 October 2021), 2017.

Mace, G. G., Zhang, Q., Vaughan, M., Marchand, R., Stephens, G., Trepte, C., and Winker, D.: A description of hydrometeor layer occurrence statistics derived from the first year of merged Cloudsat and CALIPSO data, J. Geophys. Res.-Atmos., 114, D00A26, https://doi.org/10.1029/2007JD009755, 2009.

McErlich, C., McDonald, A., Schuddeboom, A., and Silber, I.: Comparing Satellite-and Ground-Based Observations of Cloud Occurrence Over High Southern Latitudes, J. Geophys. Res.-Atmos., 126, e2020JD033607, https://doi.org/10.1029/2020JD033607, 2021.

Okamoto, H., Sato, K., and Hagihara, Y.: Global analysis of ice microphysics from CloudSat and CALIPSO: Incorporation of specular reflection in lidar signals, J. Geophys. Res.-Atmos., 115, D22209, https://doi.org/10.1029/2009JD013383, 2010.

Olsen, E., Fetzer, E., Hulley, G., Manning, E., Blaisdell, J., Iredell, L., Susskind, J., Warner, J., Wei, Z., Blackwell, W., and Maddy, E.: AIRS/AMSU/HSB version 6 level 2 product user guide, Jet Propulsion Laboratory, Version, 1, available at: https://docserver.gesdisc.eosdis.nasa.gov/repository/ Mission/AIRS/3.3_ScienceDataProductDocumentation/3.3.4_ ProductGenerationAlgorithms/V6_L2_Product_User_Guide.pdf (last access: 11 October 2021), 2013.

Parkinson, C. L.: Aqua: An Earth-observing satellite mission to examine water and other climate variables, IEEE T. Geosci. Remote, 41, 173-183, 2003.

Partain, P.: Cloudsat ECMWF-AUX auxiliary data process description and interface control document, Cooperative Institute for Research in the Atmosphere Rep, available at: ftp://ftp.cira.colostate.edu/ftp/CloudSat/Docs/ECMWF-AUX_ PDICD.P_R01.20040730.pdf (last access: 11 October 2021), 2004.

Plumb, R. A.: Stratospheric transport, J. Meteorol. Soc. Jpn. Ser. II, 80, 793-809, 2002.

Qu, Z., Huang, Y., Vaillancourt, P. A., Cole, J. N. S., Milbrandt, J. A., Yau, M.-K., Walker, K., and de Grandpré, J.: Simulation of convective moistening of the extratropical lower stratosphere using a numerical weather prediction model, Atmos. Chem. Phys., 20, 2143-2159, https://doi.org/10.5194/acp-202143-2020, 2020.

Randel, W. and Park, M.: Diagnosing observed stratospheric water vapor relationships to the cold point tropical tropopause, J. Geophys. Res.-Atmos., 124, 7018-7033, 2019.

Read, W. G., Lambert, A., Bacmeister, J., Cofield, R. E., Christensen, L. E., Cuddy, D. T., Daffer, W. H., Drouin, B. J., Fetzer, E., Froidevaux, L., Fuller, R., Herman, R., Jarnot, R. F., Jiang, J. H., Jiang, Y. B., Kelly, K., Knosp, B. W., Kovalenko, L. J., Livesey, N. J., Liu, H.-C., Manney, G. L., Pickett, H. M., Pumphrey, H. C., Rosenlof, K. H., Sabounchi, X., Santee, M. L., Schwartz, M. J., Snyder, W. V., Stek, P. C., Su, H., Takacs, L. L., Thurstans, R. P., Vömel, H., Wagner,
P. A., Waters, J. W., Webster, C. R., Weinstock, E. M., and Wu, D. L.: Aura Microwave Limb Sounder upper tropospheric and lower stratospheric $\mathrm{H}_{2} \mathrm{O}$ and relative humidity with respect to ice validation, J. Geophys. Res.-Atmos., 112, D24S35 , https://doi.org/10.1029/2007JD008752, 2007.

Rivoire, L., Birner, T., and Knaff, J. A.: Evolution of the upperlevel thermal structure in tropical cyclones, Geophys. Res. Lett., 43, 10-530, 2016

Rivoire, L., Birner, T., Knaff, J. A., and Tourville, N.: Quantifying the radiative impact of clouds on tropopause layer cooling in tropical cyclones, J. Climate, 33, 6361-6376, https://doi.org/10.1175/JCLI-D-19-0813.1, 2020.

Robinson, F. and Sherwood, S.: Modeling the impact of convective entrainment on the tropical tropopause, J. Atmos. Sci., 63, 10131027, 2006.

Rodgers, C. D.: Inverse methods for atmospheric sounding: theory and practice, vol. 2, World scientific, https://doi.org/10.1142/3171, 2000.

Romps, D. M. and Kuang, Z.: Overshooting convection in tropical cyclones, Geophys. Res. Lett., 36, L09804, https://doi.org/10.1029/2009GL037396, 2009.

Saito, M., Iwabuchi, H., Yang, P., Tang, G., King, M. D., and Sekiguchi, M.: Ice particle morphology and microphysical properties of cirrus clouds inferred from combined CALIOP-IIR measurements, J. Geophys. Res.-Atmos., 122, 4440-4462, 2017.

Sampson, C. R. and Schrader, A. J.: The automated tropical cyclone forecasting system (version 3.2), B. Am. Meteorol. Soc., 81, 1231-1240, 2000.

Sassen, K., Wang, Z., and Liu, D.: Cirrus clouds and deep convection in the tropics: Insights from CALIPSO and CloudSat, J. Geophys. Res.-Atmos., 114, D00H06, https://doi.org/10.1029/2009JD011916, 2009.

Schoeberl, M., Jensen, E., Pfister, L., Ueyama, R., Wang, T., Selkirk, H., Avery, M., Thornberry, T., and Dessler, A.: Water vapor, clouds, and saturation in the tropical tropopause layer, J. Geophys. Res.-Atmos., 124, 3984-4003, 2019.

Schoeberl, M. R., Dessler, A. E., and Wang, T.: Simulation of stratospheric water vapor and trends using three reanalyses, Atmos. Chem. Phys., 12, 6475-6487, https://doi.org/10.5194/acp12-6475-2012, 2012.

Schoeberl, M. R., Jensen, E. J., Pfister, L., Ueyama, R., Avery, M., and Dessler, A. E.: Convective hydration of the upper troposphere and lower stratosphere, J. Geophys. Res.-Atmos. 123, 4583-4593, 2018

Schubert, W. H. and McNoldy, B. D.: Application of the concepts of Rossby length and Rossby depth to tropical cyclone dynamics, J. Adv. Model. Earth Sy., 2, 7, https://doi.org/10.3894/JAMES.2010.2.7, 2010.

Schwartz, M. J., Lambert, A., Manney, G. L., Read, W. G., Livesey, N. J., Froidevaux, L., Ao, C. O., Bernath, P. F., Boone, C. D., Cofield, R. E., Daffer, W. H., Drouin, B. J., Fetzer, E. J., Fuller, R. A., Jarnot, R. F., Jiang, J. H., Jiang, Y. B., Knosp, B. W., Krüger, K., Li, J.-L. F., Mlynczak, M. G., Pawson, S., Russell III, J. M., Santee, M. L., Snyder, W. V., Stek, P. C., Thurstans, R. P., Tompkins, A. M., Wagner, P. A., Walker, K. A., Waters, J. W., and Wu, D. L.: Validation of the Aura Microwave Limb Sounder temperature and geopotential height measurements, J. Geophys. Res.Atmos., 113, D15S11, https://doi.org/10.1029/2007JD008783, 2008. 
Schwartz, M. J., Read, W. G., Santee, M. L., Livesey, N. J., Froidevaux, L., Lambert, A., and Manney, G. L.: Convectively injected water vapor in the North American summer lowermost stratosphere, Geophys. Res. Lett., 40, 2316-2321, 2013.

Solomon, S., Rosenlof, K. H., Portmann, R. W., Daniel, J. S., Davis, S. M., Sanford, T. J., and Plattner, G.-K.: Contributions of stratospheric water vapor to decadal changes in the rate of global warming, Science, 327, 1219-1223, 2010.

Stephens, G. L., Vane, D. G., Tanelli, S., Im, E., Durden, S., Rokey, M., Reinke, D., Partain, P., Mace, G. G., Austin, R., L'Ecuyer, T., Haynes, J., Lebsock, M., Suzuki, K., Waliser, D., Wu, D., Kay, J., Gettelman, A., Wang, Z., and Marchand, R. : CloudSat mission: Performance and early science after the first year of operation, J. Geophys. Res.-Atmos., 113, D00A18, https://doi.org/10.1029/2008JD009982, 2008.

Sun, Y. and Huang, Y.: An examination of convective moistening of the lower stratosphere using satellite data, Earth and Space Science, 2, 320-330, 2015.

Susskind, J., Barnet, C. D., and Blaisdell, J. M.: Retrieval of atmospheric and surface parameters from AIRS/AMSU/HSB data in the presence of clouds, IEEE T. Geosci. Remote, 41, 390-409, 2003.

Takahashi, H., Su, H., and Jiang, J. H.: Error analysis of upper tropospheric water vapor in CMIP5 models using "A-Train" satellite observations and reanalysis data, Clim. Dynam., 46, 2787-2803, 2016.

Tourville, N., Stephens, G., DeMaria, M., and Vane, D.: Remote sensing of tropical cyclones: Observations from CloudSat and A-Train profilers, B. Am. Meteorol. Soc., 96, 609-622, 2015.

Trepte, Q. Z., Minnis, P., Trepte, C., Sun-Mack, S., and Brown, R.: Improved cloud detection in CERES edition 3 algorithm and comparison with the CALIPSO vertical feature mask, in: Proc. 13th Conf. on Atmospheric Radiation and Cloud Physics, 28 June-2 July 2010, Portland, Oregon, USA, 2010.

Tseng, H.-H. and Fu, Q.: Temperature control of the variability of tropical tropopause layer cirrus clouds, J. Geophys. Res.-Atmos., 122, 11062-11075, https://doi.org/10.1002/2017JD027093, 2017.

Ueyama, R., Jensen, E. J., and Pfister, L.: Convective influence on the humidity and clouds in the tropical tropopause layer during boreal summer, J. Geophys. Res.-Atmos., 123, 7576-7593, 2018.

Wang, Z., Vane, D., Stephens, G., and Reinke, D.: Level 2 combined radar and lidar cloud scenario classification product process description and interface control document, JPL Rep, California Institute of Technology, Jet Propulsion Laboratory Doc., 22, available at: https://www.cloudsat. cira.colostate.edu/cloudsat-static/info/dl/2b-cldclass-lidar/ 2B-CLDCLASS-LIDAR_PDICD.P_R04.20120522.pdf (last access: 11 October 2021), 2012.
Waters, J. W., Froidevaux, L., Harwood, R. S., Jarnot, R. F., Pickett, H. M., Read, W. G., Siegel, P. H., Cofield, R. E., Filipiak, M. J., Flower, D. A., Holden, J. R., Lau, G. K., Livesey, N. J., Manney, G. L., Pumphrey, H. C., Santee, M. L., Wu, D. L., Cuddy, D. T., Lay, R. R., Loo, M. S., Perun, V. S., Schwartz, M. J., Stek, P. C., Thurstans, R. P., Boyles, M. A., Chandra, K. M., Chavez, M. C., Chen, G.-S., Chudasama, B. V., Dodge, R., Fuller, R. A., Girard, M. A., Jiang, J. H., Jiang, Y., Knosp, B. W., LaBelle, R. C., Lam, J. C., Lee, K. A., Miller, D., Oswald, J. E., Patel, N. C., Pukala, D. M., Quintero, O., Scaff, D. M., Van Snyder, W., Tope, M. C., Wagner, P. A., and Walch, M. J.: The earth observing system microwave limb sounder (EOS MLS) on the Aura satellite, IEEE T. Geosci. Remote, 44, 1075-1092, 2006.

Wetherald, R. and Manabe, S.: Cloud feedback processes in a general circulation model, J. Atmos. Sci., 45, 1397-1416, 1988.

Winker, D. M., Pelon, J., Coakley Jr., J. A., Ackerman, S. A., Charlson, R. J., Colarco, P. R., Flamant, P., Fu, Q., Hoff, R. M., Kittaka, C., Kubar, T. L., Le Treut, H., Mccormick, M. P., Mégie, G., Poole, L., Powell, K., Trepte, C., Vaughan, M. A., and Wielicki, B. A.: The CALIPSO mission: A global 3D view of aerosols and clouds, B. Am. Meteorol. Soc., 91, 1211-1230, 2010.

World Meteorological Organisation (WMO): Meteorology - a three-dimensional science, WMO Bull., 6, 134-138, available at: https://library.wmo.int/doc_num.php?explnum_id=6960 (last access: 11 October 2021), 1957.

Wright, J. S. and Fueglistaler, S.: Large differences in reanalyses of diabatic heating in the tropical upper troposphere and lower stratosphere, Atmos. Chem. Phys., 13, 9565-9576, https://doi.org/10.5194/acp-13-9565-2013, 2013.

Wright, J. S., Sun, X., Konopka, P., Krüger, K., Legras, B., Molod, A. M., Tegtmeier, S., Zhang, G. J., and Zhao, X.: Differences in tropical high clouds among reanalyses: origins and radiative impacts, Atmos. Chem. Phys., 20, 8989-9030, https://doi.org/10.5194/acp-20-8989-2020, 2020.

Yang, Q., Fu, Q., and Hu, Y.: Radiative impacts of clouds in the tropical tropopause layer, J. Geophys. Res.-Atmos., 115, D00H12, https://doi.org/10.1029/2009JD012393, 2010.

Young, A. H., Bates, J. J., and Curry, J. A.: Application of cloud vertical structure from CloudSat to investigate MODIS-derived cloud properties of cirriform, anvil, and deep convective clouds, J. Geophys. Res.-Atmos., 118, 4689-4699, 2013. 